\title{
International consensus on lung function testing during the COVID-19 pandemic and beyond
}

\author{
Aisling McGowan ${ }^{1,2}$, Pierantonio Laveneziana ${ }^{3,4}$, Sam Bayat $\mathbb{1}^{5,6}$, Nicole Beydon $\mathbb{D}^{7}$, P.W. Boros $\mathbb{1}^{8}$, \\ Felip Burgos ${ }^{9}$, Matjaž Fležar ${ }^{10,11}$, Monika Franczuk ${ }^{8}$, Maria-Alejandra Galarza ${ }^{3,4}$, Adrian H. Kendrick ${ }^{12,13,14}$, \\ Enrico Lombardi ${ }^{15}$, Jellien Makonga-Braaksma ${ }^{16}$, Meredith C. McCormack ${ }^{17}$, Laurent Plantier $\mathbb{1}^{18,19}$, \\ Sanja Stanojevic ${ }^{20}$, Irene Steenbruggen $\mathbb{B}^{21}$, Bruce Thompson ${ }^{22}$, Allan L. Coates ${ }^{23}$, Jack Wanger ${ }^{24}$, \\ Donald W. Cockcroft ${ }^{25}$, Bruce Culver ${ }^{26}$, Karl Sylvester ${ }^{27,28}$ and Frans De Jongh ${ }^{29}$
}

\begin{abstract}
${ }^{1}$ Dept of Respiratory and Sleep Diagnostics, Connolly Hospital, Dublin, Ireland. ${ }^{2}$ School of Physics, Clinical and Optometric Sciences, Technological University Dublin, Dublin, Ireland. ${ }^{3}$ Sorbonne Université, INSERM, UMRS1158 Neurophysiologie Respiratoire Expérimentale et Clinique, Paris, France. ${ }^{4}$ AP-HP, Groupe Hospitalier Universitaire APHP-Sorbonne Université, Service des Explorations Fonctionnelles de la Respiration, de l'Exercice et de la Dyspnée (Département R3S), Paris, France. ${ }^{5}$ Centre Hospitalier Universitaire de Grenoble Alpes, Unité d'Explorations Fonctionnelles, Cardiorespiratoires, Grenoble, France. ${ }^{6}$ Université Grenoble Alpes - INSERM UA7, Rayonnement Synchrotron pour la Recherche Biomédicale (STROBE), Grenoble, France. ${ }^{7}$ Unité Fonctionnelle de PhysiologieExplorations Fonctionnelles Respiratoires, AP-HP Sorbonne Université, Hôpital Armand-Trousseau, Paris, France. ${ }^{8}$ Lung Pathophysiology Dept, National Tuberculosis and Lung Diseases Research Institute, Warsaw, Poland. ${ }^{9}$ Department of Pulmonary Medicine, Hospital Clínic, Institut d'Investigacions Biomèdiques August Pi I Sunyer, Universitat de Barcelona, CIBERES, Barcelona, Spain. ${ }^{10}$ University Clinic of Respiratory and Allergic Diseases, Golnik, Slovenia. ${ }^{11}$ Medical Faculty, University of Ljubljana, Ljubljana, Slovenia. ${ }^{12}$ Dept of Respiratory Medicine, University Hospitals Bristol \& Weston NHS Trust, Bristol, UK. ${ }^{13}$ University of West of England, Bristol, UK. ${ }^{14}$ School of Physiology, Pharmacology and Neurophysiology, University of Bristol, Bristol, UK. ${ }^{15}$ Pediatric Pulmonary Unit, Anna Meyer Pediatric University Hospital, Florence, Italy. ${ }^{16}$ Lung Function Dept, Meander Medisch Centrum, Amersfoort, The Netherlands. ${ }^{17}$ Pulmonary Function Laboratory, Pulmonary and Critical Care Medicine, Johns Hopkins University, Baltimore, MD, USA. ${ }^{18}$ Pulmonology and Lung Function Testing, CHRU de Tours, Tours, France. ${ }^{19}$ University of Tours, CEPR/Inserm UMR1100, Tours, France. ${ }^{20}$ Dept of Community Health and Epidemiology, Dalhousie University, New Brunswick, NS, Canada. ${ }^{21}$ Pulmonary Function Dept, Isala Hospital, Zwolle, The Netherlands. ${ }^{22}$ Faculty of Health, Arts and Design, Swinburne University of Technology, Victoria, Australia. ${ }^{23}$ Division of Respiratory Medicine, Dept of Pediatrics, Physiology and Environmental Medicine, Research Institute, Hospital for Sick Children, University of Toronto, Toronto, ON, Canada. ${ }^{24}$ Pulmonary Function Testing and Clinical Trial Consultant, Rochester, MN, USA. ${ }^{25}$ Division of Respirology, Critical Care and Sleep Medicine, Dept of Medicine, University of Saskatchewan, Saskatoon, SK, Canada. ${ }^{26}$ Pulmonary, Critical Care and Sleep Medicine, University of Washington, Seattle, WA, USA. ${ }^{27}$ Cambridge Respiratory Physiology, Cambridge University Hospital, Cambridge, UK. ${ }^{28}$ Royal Papworth Hospital, Cambridge, UK. ${ }^{29}$ Lung Function Lab, Medisch Spectrum Twente, Enschede, The Netherlands.
\end{abstract}

Corresponding author: Aisling McGowan (aisling.mcgowan1@hse.ie)

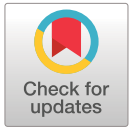

This version is distributed under the terms of the Creative Commons Attribution NonCommercial Licence 4.0. For commercial reproduction rights and permissions contact permissions@ersnet.org
Shareable abstract (@ERSpublications)

International expert consensus statement describing the infection protection control strategies for restoration and continuity of lung function testing services during \#COVID19 pandemic and beyond https://bit.ly/3kn47Gy

Cite this article as: McGowan A, Laveneziana P, Bayat S, et al. International consensus on lung function testing during the COVID-19 pandemic and beyond. ERJ Open Res 2022; 8: 00602-2021 [DOI: 10.1183/23120541.00602-2021].

\section{Abstract}

Coronavirus disease 2019 (COVID-19) has negatively affected the delivery of respiratory diagnostic services across the world due to the potential risk of disease transmission during lung function testing. Community prevalence, reoccurrence of COVID-19 surges and the emergence of different variants of SARS-CoV-2 have impeded attempts to restore services. Finding consensus on how to deliver safe lung function services for both patients attending and for staff performing the tests are of paramount importance.

This international statement presents the consensus opinion of 23 experts in the field of lung function and respiratory physiology balanced with evidence from the reviewed literature. It describes a robust roadmap for restoration and continuity of lung function testing services during the COVID-19 pandemic and beyond. 
Received: 23 Oct 2021 Accepted: 31 Oct 2021

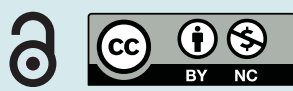

Important strategies presented in this consensus statement relate to the patient journey when attending for lung function tests. We discuss appointment preparation, operational and environmental issues, testing room requirements including mitigation strategies for transmission risk, requirement for improved ventilation, maintaining physical distance and use of personal protection equipment. We also provide consensus opinion on precautions relating to specific tests, filters, management of special patient groups and alternative options to testing in hospitals.

The pandemic has highlighted how vulnerable lung function services are and forces us to re-think how long-term mitigation strategies can protect our services during this and any possible future pandemic. This statement aspires to address the safety concerns that exist and provide strategies to make lung function tests and the testing environment safer when tests are required.

Introduction

Coronavirus disease 2019 (COVID-19) is a disease caused by severe acute respiratory syndrome coronavirus 2 (SARS-CoV-2), primarily impacting the respiratory system. Presentation and course of this disease are heterogeneous from mild to serious disease and may lead to admission to the intensive care unit due to respiratory failure. Lung function tests (LFTs) require patients to perform active and maximal respiratory manoeuvres while in close proximity to staff conducting the tests. LFTs often induce cough or other symptoms, so there is a high potential risk for disease transmission during patient testing [1, 2]. This document is an international expert consensus opinion incorporating considered published evidence since the onset of this pandemic. We provide detailed information on the potential for transmission of this disease during testing and the precautions that should be considered to protect both staff and patients. These precautions are likely to be relevant not only to SARS-CoV-2 and variants, but also to other pathogens and any future respiratory pandemic.

Lung function professionals work routinely with patients who present with respiratory symptoms increasing the risk of exposure when dealing with COVID-19 patients. Although patient screening before LFTs is often mandatory in many institutions, some patients may present for testing who are asymptomatic, pre-symptomatic or with false-negative reverse transcription (RT)-PCR test results. All patients must remove their face masks during the test session. This increases the potential risk of virus transmission to staff, the testing equipment, the testing environment and also to other patients entering the same space for their test session on the same equipment.

During the peak of the first wave of the pandemic in early 2020, the availability of lung function services was severely limited to those deemed clinically urgent, e.g. oncology treatment and preoperative assessment. In the post-peak phase with varying degrees of community prevalence, services have cautiously resumed. Most countries have now endured several surges and have had to reassess service delivery and repeatedly reduce services during periods of high local community transmission. The lack of a consensus agreement on how best to resolve the problem has led to this "stop/start" approach and has resulted in long waiting lists for tests. There is a need to provide a robust roadmap not only to restore services but for continuity of lung function services, while also ensuring the safety of both staff and patients during the pandemic and beyond.

A return to pre-pandemic service levels is strongly encouraged but must take into consideration the safety constraints to be implemented in order to minimise the transmission risk to staff and patients attending for LFTs.

Important factors that should be considered when performing LFTs are the:

- individual patient being tested, their medical conditions and needs, e.g. those requiring additional assistance when performing the tests such as neuromuscular disease and paediatric patients

- transmissible risk of each test to the staff, the patient or testing environment, i.e. via contact, droplet and aerosol transmission as the patient cannot wear a protective face mask during the test and/or is not capable of reapplying the mask between tests

- staff member is required to vigorously and loudly coach the patient during testing and demonstrate the different manoeuvres in close proximity to the patient (mask leakage and mask fit are important considerations)

- $\quad$ staff personal protective equipment (PPE) and cleaning procedures for equipment and testing area

- duration of the test (potential time of the exposure)

- complexity of each test being performed

- potential for effort-induced cough (many tests induce cough due to effort)

- availability and reliability of room ventilation (natural or artificial), guaranteed fresh air exchange, air purification and wait time for droplet settling between patients (droplet pause) 
- room temperature and humidity

- staff and patient vaccination status and time period since last vaccination dose

As with other areas of respiratory medicine, there is a paucity of published evidence relating specifically to the transmission of SARS-CoV-2 during LFTs. We present the most relevant and pertinent information and evidence from the recent literature to support our consensus opinion. We will discuss the provision of lung function services and evidence for approaches during all levels of community prevalence. Such approaches will vary over time from country to country and are in some cases based on local community spread. Vaccination programmes are underway; however, precautions must be continued until the programmes have been completed and the effectiveness of the vaccines on emerging SARS-CoV-2 variants of concern has been fully established.

Scope

This article follows the path of the typical patient journey when referred for LFTs, from patient screening, demands on waiting and testing rooms, specific LFTs, safety issues and consideration of specific patient groups.

\section{Methodology and consensus approach}

A group of international experts in lung function collaborated to rapidly prepare our first statement on LFTs during the first wave of the COVID-19 pandemic [3]. Our group initially convened on April 23, 2020 to discuss the urgent need for a published statement in response to many requests from international colleagues. We prioritised our efforts, reviewed the available literature and published statements from international thoracic and professional societies [3-14]. On May 1, 2020, a short document was submitted to the European Respiratory Society (ERS) and was posted on the ERS COVID-19 resource centre website in the "guidelines and recommendations directory".

Our approach for this article is to present updated evidence collected and reviewed to substantiate our original statement (figure 1). A database was prepared in which all of the authors could upload documents related to LFTs and COVID-19 searches, but also for general documents on ventilation, cleaning of rooms/ equipment and related to evidence found for other transmissible pulmonary diseases such as tuberculosis and SARS-CoV-1. Experts were assigned to subgroups to review the literature on specific topics and produced written drafts that were then reviewed, edited and agreed by the entire group.

\section{Strengths of this statement}

Our statement has several strengths. We are responding to an urgent need for more detailed procedural information for lung function practitioners worldwide. We base our statement on the most recent, relevant COVID-19 statements from highly respected international and national lung function organisations, peer-reviewed studies and evidence-based sources. The authors represent an international group of lung function professionals with extensive clinical experience in this area. This article provides a more detailed

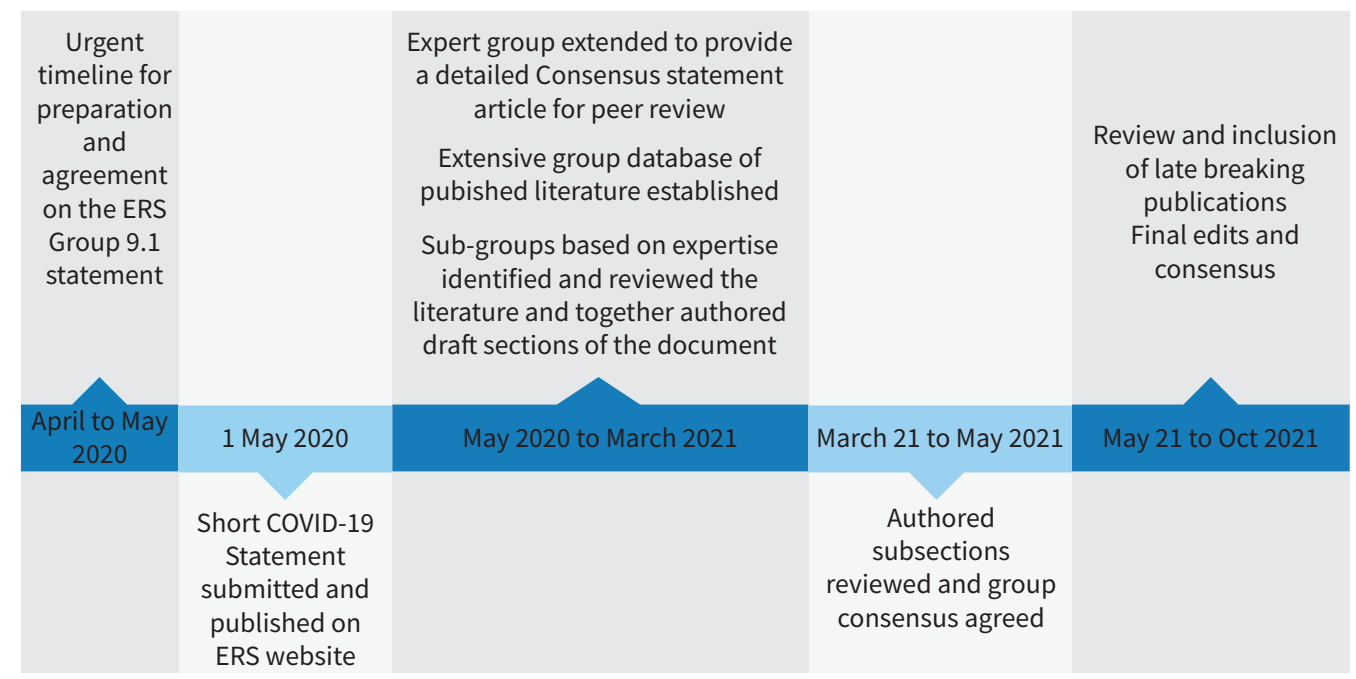

FIGURE 1 The consensus statement process and timeline. ERS: European Respiratory Society. 
approach to assist lung function professionals to restore and maintain LFT service levels during this and any future pandemic.

\section{Limitations of this statement}

Our statement also has limitations. Considering the sudden presentation of COVID-19, this statement is based on the evidence to date and may change as we learn more about the natural history and ongoing development of this disease and its variants. Moreover, many published sources are not based on double-blind placebo-controlled studies or can follow the GRADE system since the required articles do not exist. There is a lack of evidence-based research conducted on the transmissibility of recognised airborne diseases and SARS-CoV-2 during LFTs. Another issue is that airborne transmission is difficult to demonstrate fully due to known technological limitations [15]. This potentially underestimates the emission of fine expiratory particles produced via breathing, talking, coughing, sneezing or performing LFTs. Further work will be required in this area.

\section{Section 1: Transmission, environmental and equipment considerations}

Infection control protection has always been important in lung function laboratories. Specific requirements were suggested as far back as 1997 in the ERS/American Thoracic Society (ATS) report series on lung volume equipment and infection control [16]. The authors considered general rules of infection control that included use of gloves, hand hygiene, staff screening for infection, vaccination, negative pressure rooms for patients who frequently cough, justification of the clinical need for testing patients with high-risk infection, laboratory surface cleaning between patients, equipment cleaning and use of disposable bacterial viral filters for LFTs. All these considerations are still relevant today as a minimum standard during this and any future pandemic.

Infection control protection strategies must include an assessment of risk involving the frequency and consequences of a detrimental event occurring. The Centers for Disease Control and Prevention (CDC) and World Health Organization (WHO) have recognised that there are three main potential transmission routes of SARS-CoV-2 [17-19]:

- Airborne transmission: an infection spread through exposure to virus-containing respiratory droplets comprised of smaller droplets and particles that can remain suspended in the air over long distances (usually $>2 \mathrm{~m}$ ) and for a long time (typically hours).

- Droplet transmission: an infection spread through exposure to virus-containing droplets ranging in size exhaled by an infectious person. Transmission is most likely to occur when someone is within $2 \mathrm{~m}$ of the infectious person.

- Contact transmission: an infection spread through direct contact with an infectious person or with an article or surface (fomite transmission) that has become contaminated.

SARS-CoV-2 can be transmitted via droplets and aerosols of various sizes, often produced during exhalation, breathing, speaking, singing, coughing and sneezing, and can remain suspended in the air for many minutes or hours [20-22]. The exposure risk increases when occupying indoor spaces with poor ventilation for prolonged periods. It is especially important when in close proximity to infected individuals. This can lead to an increase in the concentration of suspended small droplets and aerosols carrying the infectious virus and therefore presents a potential risk. Several respiratory pathogens are known to spread through small respiratory aerosols, which can float and travel in air flows, infecting people who inhale them at short and long distances from the infected person [23]. Expelled droplets rapidly lose water through evaporation, with the smaller droplets transforming into long-lived aerosol. Once inhaled, the virus-laden aerosols can deposit in different parts of the respiratory tract, and smaller aerosols can penetrate deep into the alveolar region of the lungs. Small speech aerosol can be inhaled deep into the lower respiratory tract and cause severe disease [23]. In spaces with inadequate ventilation aerosols accumulate, which elevates the risk of direct infection.

With regard to LFTs, some researchers have argued that aerosol exposure is underappreciated and warrants widespread targeted interventions. Their published data showed that when exertional respiratory activities such as cough, forced expiratory volume (FVC) and moderate exercise were compared to quiet breathing, the exertional activities yielded a 370.8-fold, 227.6-fold and 58.0-fold increase in particle counts (0.5$25 \mu \mathrm{m})$, respectively [2]. It is common for patients to exhibit effort-induced cough while undertaking LFTs, regardless of any specific underlying condition or symptoms [24]. This is also evident in studies using healthy volunteers [1, 2]. Respiratory activities such as coughing produce droplets and aerosols at higher velocities than speaking, and aerosols can remain suspended in air for many seconds to hours [20]. We must therefore assume all patients carry equal risk of cough when performing LFTs. The Global 
Initiative for Asthma (GINA) organisation in 2020 amended their COVID-19 infection control recommendations to include "follow aerosol, droplet, and contact precautions if spirometry is needed" [25]. Other studies have reported that cough during LFTs generates considerably higher aerosol particle counts than other specific respiratory activities [26-28]. Li et al. [1, 20] confirmed previous evidence that LFTs generate aerosol particles even when a breathing filter is used; they concluded that use of a filter reduced the peak particulate concentration during testing. A peak was observed when patients were breathing or coughed off the mouthpiece, thus recommending that a face mask be replaced as soon as the patient removes themselves from the mouthpiece. Their study data suggested that fresh air ventilation in the testing room reduced ambient particles. They demonstrated that a larger room size and higher rate of ventilation reduced the ambient particle clearance rate. They stated that exposure to staff members during and after LFTs is independent of clearance rate, so to avoid transmission of infection, high-level PPE must be used during this pandemic.

There remains an absence of evidence of the detection of viable virus in air for SARS-CoV-2 as is the case for other accepted airborne diseases such as tuberculosis, measles and chickenpox. However multiple studies have shown that patients produce more aerosols through simple breathing, talking and coughing than from many aerosol-generating procedures (AGPs) [29-32]. A survey of pulmonary function testing laboratories in the USA reported high adherence with the recommendations from the ATS and ERS and the majority considering LFTs as AGPs in line with recent evidence [33]. Almost 75\% of laboratories were fully operational again demonstrating the resilience and adaptability necessary to cope with the ever-changing demands of safely providing LFT services during a pandemic. In the absence of any and/or conclusive evidence that LFTs do not carry a risk of virus transmission, and that SARS-CoV-2 variants such as Delta exhibit greatly increased transmissibility [34], we endorse a precautionary approach to safety procedures. It is therefore of the utmost importance during testing that the safety of our patients and staff are prioritised. We will discuss the practice of these safety precautions during specific LFTs in this statement. For the purposes of this document, the term LFTs refers to all tests listed in table 1.

\section{Personal protective equipment}

International guidance recommends that procedures that are likely to generate droplets and aerosols should be minimised, or where unavoidable, workers should wear appropriate respiratory protection. Common infection control guidance recommends that workers who are in close contact with patients should wear surgical masks to reduce exposure to large droplets. A recent systematic review including six studies over four countries showed that wearing a surgical mask reduced risk of COVID-19 infection by nearly $70 \%$ in healthcare workers [35]. Surgical masks are known to provide a degree of protection against droplets and splashing, and comply with the British Standard (BS EN 14683:2005) [36]. This states that "The surgical masks intended to be used in operating theatres and healthcare settings with similar requirements are designed to protect the working environment and not the wearer. When the primary intention is to protect

TABLE 1 Summary of consensus on protection measures of lung function staff

\begin{tabular}{|c|c|c|c|c|}
\hline Test type & Filter & Mask ${ }^{\#}$ & Apron/Gown & Goggles/shields \\
\hline Lung function tests include: spirometry, lung volumes methods, $D_{\mathrm{Lco}}$ & + & FFP2/N95 & + & + \\
\hline Bronchodilator administration pMDI, DPI & - & FFP2/N95 & + & + \\
\hline Bronchodilator administration (Neb) (filter on expiratory port) & + & FFP3/ N99 & + & + \\
\hline Bronchial challenge testing (BCT) All types Ideally negative pressure room & + & FFP3/ N99 & + & + \\
\hline Dosimeter/nebuliser BCT (filter on expiratory port of device) & + & FFP3/ N99 & + & + \\
\hline CPET ideally negative pressure room & - & FFP3/N99 & + & + \\
\hline 6MWT & - & IIR/FFP2 & + & - \\
\hline FOT & + & FFP2/N95 & + & + \\
\hline$F_{\mathrm{ENO}}$ use in-circuit filter & + & FFP2/N95 & + & + \\
\hline Nasal NO use in-circuit filter & + & FFP2/N95 & - & - \\
\hline Capnography use in-circuit filter & - & FFP2/N95 & + & + \\
\hline MIPS/MEPS & + & FFP2/N95 & + & + \\
\hline SNIFF test & - & FFP2/N95 & + & + \\
\hline
\end{tabular}

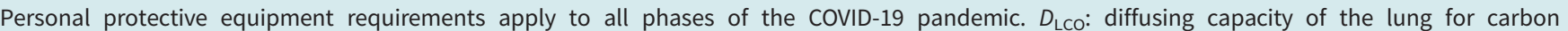
monoxide; pMDI: pressured metered-dose inhaler; DPI: dry powder inhalers; Neb: nebuliser; CPET: cardiopulmonary exercise testing; 6MWT: 6-min walk test; FOT: forced oscillation technique; $F_{\mathrm{ENO}}$ : exhaled nitric oxide; MIPs: maximal inspiratory pressures; MEPs: maximal expiratory pressures; +: required; -: not required. "\#: based on risk assessment and local recommendations. Gowns/aprons, gloves and eye protection as recommended by the World Health Organization [65]. 
TABLE 2 Mean values of the reduction factors, fit factor, required minimum efficiency and assigned protection factor for the grouped range of filtering facepieces and surgical masks [36]

\begin{tabular}{|c|c|c|c|c|c|c|}
\hline \multirow[t]{2}{*}{ Mask type } & \multicolumn{2}{|c|}{ Reduction factor } & \multicolumn{2}{|c|}{ Fit factor } & \multirow{2}{*}{$\begin{array}{l}\text { Required minimum filter } \\
\text { efficiency } \%\end{array}$} & \multirow{2}{*}{$\begin{array}{l}\text { Assigned protection } \\
\text { factor }\end{array}$} \\
\hline & $\begin{array}{l}\text { Ambient } \\
\text { particles }\end{array}$ & $\begin{array}{l}\text { Simulated } \\
\text { sneeze }\end{array}$ & $\begin{array}{l}\text { Ambient } \\
\text { particles }\end{array}$ & $\begin{array}{l}\text { Simulated } \\
\text { sneeze }\end{array}$ & & \\
\hline FFP3 & 228 & 145 & 766 & 167 & 99 & 20 \\
\hline FFP2 & 95 & 54 & 258 & 52 & 94 & 10 \\
\hline FFP1 & 29 & 42 & 1791 & 335 & 80 & 4 \\
\hline Surgical mask - tie & 4 & 2 & 4 & 2 & Unknown & Unknown \\
\hline Surgical mask - strap & 5 & 2 & 9 & 2 & Unknown & Unknown \\
\hline Surgical mask - all & 4 & 2 & 5 & 2 & Unknown & Unknown \\
\hline
\end{tabular}

the wearer from infection, the use of respiratory protective devices should be considered”. Surgical masks are not designed to fit closely to the wearer's face and are not intended to offer protection against airborne particles. They do not have the filtering efficiencies or protection factors required for adequate respiratory protection. A good facial seal appears to be key to the overall performance of a mask [37, 38]. Disposable filtering facepieces (FFP) are deemed suitable to use when the wearer has undergone and passed a mask fit test. The European PPE Directive 89/686/EEC that covers respiratory protective equipment (RPE) excludes surgical masks, and they are not certified for use as RPE in the UK. Surgical masks can be certified compliant with the Medical Devices Directive and be "CE" marked; however, surgical masks do not include respiratory protection under the PPE Directive. Several studies have evaluated the relative levels of protection provided by both surgical masks and respirators against aerosols. Surgical masks have been shown to reduce mean exposure to cough-generated aerosol by 6-fold, but FFP respirators will reduce exposure 100-fold or higher [21, 39, 40]. Another study on mask protection against influenza bioaerosols demonstrated that "Live viruses could be detected in the air behind all surgical masks tested. By contrast, properly fitted respirators could provide at least a 100-fold reduction”. Data from this study comparing different face mask types and their protection, fit and filter efficiency are presented in table 2.

It is possible that loud vocalisation poses a potential transmission risk to the patient by generating greater particle emission in asymptomatic individuals [41, 42]. LFTs require vigorous and continuous coaching of all patients during each test session. This often requires loud articulation of instructions, encouragement and often demonstration of the test technique prior to and during each test trial. It is therefore possible that loud vocalisation poses a potential transmission risk to the patient by asymptomatic staff wearing poorly fitted face masks. Reducing risk of viral transmission to all patients including those who are immunocompromised is of the utmost importance.

\section{Environmental considerations}

Room cleaning must always be undertaken post droplet pause (aerosol settling period). The CDC provides examples of air exchange rates, appropriate droplet pause periods and the time for airborne-contaminant removal as presented in table 3 [43]. Ventilation rates are measured in terms of air changes per hour, which is a measure of the air flow rate relative to the room size. This measure can be useful to understand how quickly the ventilation removes contaminants from the air. A ventilation rate of six air changes per hour would mean that six times the volume of the room is provided every hour by the ventilation system. However, this does not mean that all the air is changed six times in the hour - the new air mixes with the air that is already in the room causing dilution with time. At six air changes per hour, 95\% of the contaminants in the air would be removed in $30 \mathrm{~min}$ [43].

The WHO recommends room cleaning procedures and cleaning agents effective against the virus, the use of which should be agreed upon locally [44]. Other options for environmental cleaning are high-efficiency particulate air (HEPA) room filtration and ozone cleaning. Ozone room cleaning devices may be used only outside clinic hours under strict safety restrictions [45]. Since the virus is surrounded by a fluid layer, HEPA filters class H13 (filter capacity 99.97\%) and higher should theoretically be effective in removing all virus particles from the filtered air (see Section 4 Testing room precautions for more information). Ultraviolet (UV) germicidal irradiation can be used as a supplemental air cleaning measure. UV radiation rapidly inactivates the virus; however, it must be used with caution. Available options are HEPA/UVC portable air cleaners, high level (upper room) UV lamps or placing UV lamps inside ducts that remove air from rooms to disinfect the air before it is recirculated. However, this measure alone cannot replace HEPA 


\begin{tabular}{lrr}
$\begin{array}{l}\text { TABLE } 3 \\
\text { Healthcare Facilities }\end{array}$ - airborne-contaminant table \\
$\begin{array}{l}\text { Air exchange per } \\
\text { hour (ACH) }\end{array}$ & $\begin{array}{c}\text { Time }(\mathrm{min}) \text { required for removal of } 99 \% \\
\text { of airborne contaminants }\end{array}$ & $\begin{array}{c}\text { Time }(\mathrm{min}) \text { required for removal of } 99.9 \% \\
\text { of airborne contaminants }\end{array}$ \\
\hline 2 & 138 & 207 \\
4 & 69 & 104 \\
6 & 46 & 69 \\
8 & 35 & 52 \\
10 & 28 & 41 \\
12 & 23 & 35 \\
15 & 18 & 28 \\
20 & 14 & 21 \\
\hline 50 & 6 & 8 \\
\hline
\end{tabular}

Time to remove aerosol particles based on air exchange rate per hour (Airborne-contaminant removal Table).

filtration [46]. Portable HEPA air purifiers, ultraviolet light systems and combined portable HEPA devices offer less expensive options [47]. Portable HEPA air purifiers offer the possibility to reduce the aerosol load substantially in closed rooms or where fresh air intake is not possible. Only if the air is drawn continuously through the filter, then the risk of infection from respirable aerosol is likely to be reduced [47].

Temperature has a direct impact on the survival and transmission of viruses in aerosols, favouring lower air temperatures. Relative humidity modulates the evaporation rate and size of aerosols thus affecting their transportation and viability.

\section{Equipment considerations}

All equipment must be cleaned according to manufacturer guidance and local policy. Where possible and practicable disposable covers for exposed equipment parts should be used, e.g. covers for equipment arms (see Section 4 Testing room precautions). Equipment parts may have to be removed and cleaned more frequently during peak periods of any pandemic. Bacterial/viral filters should be used unless it adversely affects the test results (see Section 5 Lung function test procedures during COVID-19 pandemic). Filters must be used even on equipment that routinely has not required such filtration in the past, e.g. ultrasonic spirometers. The implications of using additional filters on some equipment must be recognised and appropriate measures taken, e.g. equipment dead space and measurement accuracy and verification of calibration; therefore, consultation with the manufacturers of the equipment and filters may be required.

The risk of cross-infection depends on several factors including the virulence of the organism and the health status of the patient under investigation. Precautions while conducting LFTs must include protective strategies for aerosol, droplet and contact potential. Minimising the risk of airborne transmission requires measures to avoid inhalation of infectious aerosols, including ventilation, air filtration, reduction of crowding and time spent indoors, use of masks whenever indoors, attention to mask quality and fit based on particle size, and higher grade protection for healthcare staff and front-line workers [48].

\section{Section 2: Referral, triage, PCR test}

\section{a) Referral}

Referral for LFTs during the COVID-19 pandemic needs precisely described indications for urgent or essential tests. In this context, all requested tests need to be justified by the referrer and triaged by the staff managing the service. It may be necessary to postpone testing to a later date or until it is safer to do so (figure 2).

An example of how to triage referrals based on their urgency is:

- Category 1 - Urgent/Essential - Required for the initiation of life-saving interventions, e.g. chemotherapy or surgery.

- Category 2 - Non-urgent but with the potential to be life-limiting, e.g. to determine the appropriateness of anti-fibrotic therapy in interstitial lung disease, biological treatment in severe asthma patients.

- Category 3 - Routine - Delaying testing will not result in acute harm to the patient.

- Category 4 - Consider alternative approaches to test patients outside the hospital, e.g. via home testing via live video instruction and coaching or "in-car" spirometry [49]; also see figure 2. These options are 


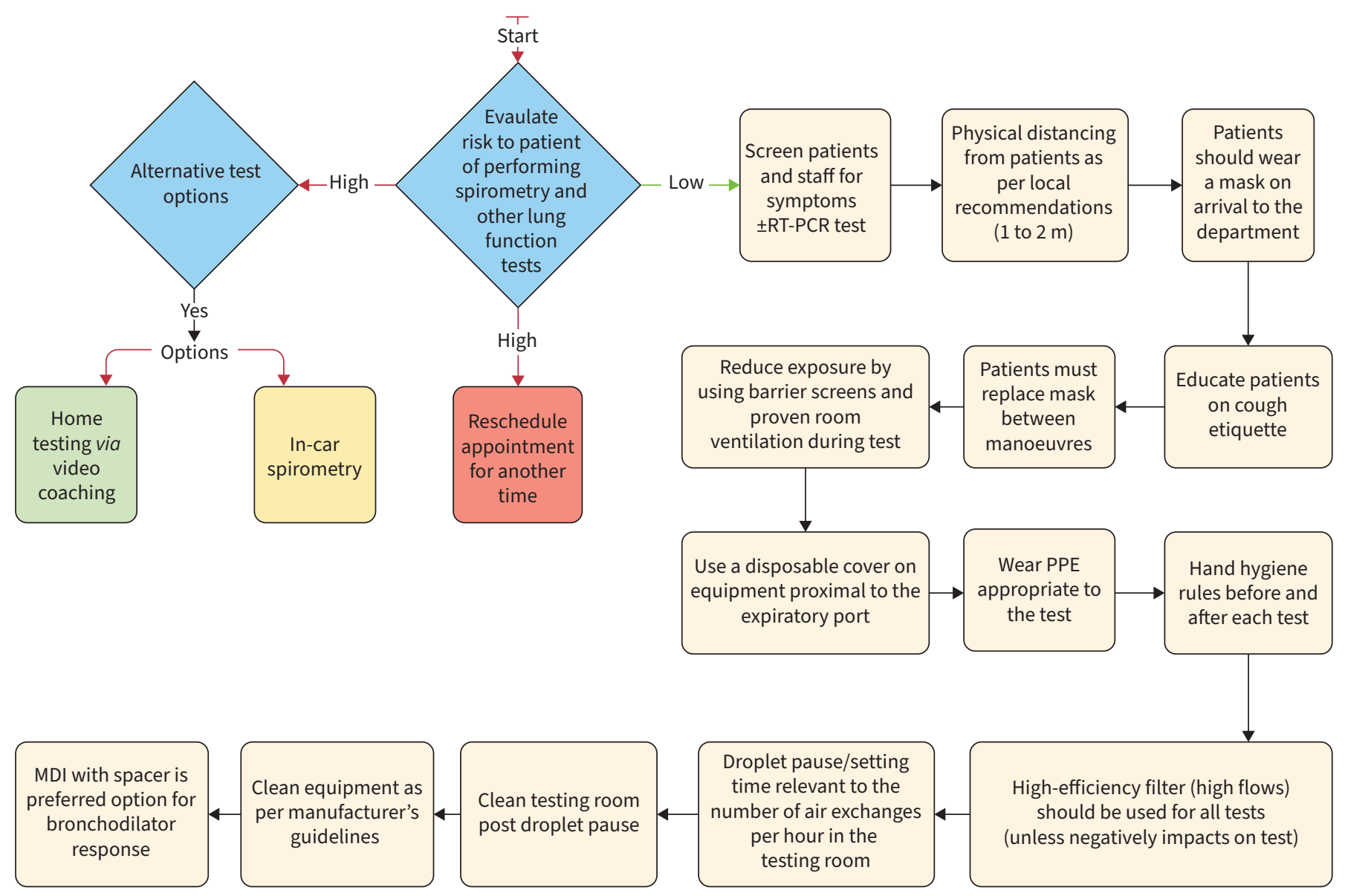

FIGURE 2 Workflow for spirometry during COVID-19 era. PPE: personal protective equipment; MDI: metered-dose inhaler. 
briefly discussed in Section 7 Testing outside the hospital and Section 8 Telemedicine/video-coached spirometry.

\section{b) Triage}

Preparation for the patient appointment should include a triage process including a completed patient questionnaire within $72 \mathrm{~h}$ before the appointment and a second triage check immediately before the patient tests. The patient should be advised to attend alone but where this is not possible, it is advisable to triage anyone accompanying the patient, e.g. parent, guardian, caregiver and interpreter. A triage questionnaire typically consists of a list of questions requiring a YES or NO answer [3]. The questions should be specific and consider as many symptoms of COVID-19 as are currently known, e.g. high temperature, cough, change in taste and smell, muscle or bone pain, conjunctivitis, sinus congestion, runny nose and sneezing. Body temperature checks and pulse oximetry immediately before testing is advisable as there is evidence of "silent hypoxaemia" cases in asymptomatic or pre-symptomatic patients [50]. Questions on the patient's history within the previous 14 days of the test and exposure to any known contacts with COVID-19 within this period may be useful in infection risk assessment.

The list of symptoms will be dependent on the variants circulating in the local community.

\section{c) RT-PCR test}

RT-PCR testing was commonly carried out before hospital visits during the first wave of the pandemic. As the prevalence decreased, this practice became less commonly used as many patients had negative PCR tests and some tests can produce false-negative results. It is assumed that the incubation period is up to 14 days, with the majority of patients developing symptoms between 2.2 to 11.5 days (median 5.0 days) [51]. The reported time to RT-PCR for SARS-CoV-2 conversion is 19.5 to 22.0 days since the day of symptoms onset. The recovery time is longer in elderly patients and patients with a severe course of the disease. One reported extended time of viral shedding in survivors was 37 and 42 days [52]. A wait time of 30 days post-COVID-19 infection was used by many centres as a precautionary measure until supporting evidence on safety emerged and that all precautionary measures should be consistently followed, e.g. PPE, droplet pause and cleaning.

Recent publications have shown that there is an inability to differentiate between what are infective and non-infective viruses (dead or antibody-neutralised) and that it remains a major limitation of nucleic acid detection [53]. For patients with mild-to-moderate COVID-19, replication-competent virus has not been recovered after 10 days following symptom onset [54]. Recovery of replication-competent virus between 10 and 20 days after symptom onset has been documented in some persons with severe COVID-19 that, in some cases, was complicated by immunocompromised state [55]. However, in this series of patients, it was estimated that $88 \%$ and $95 \%$ of their specimens no longer yielded replication-competent virus after 10 and 15 days, respectively, following symptom onset. No viable virus in sputum or at the nasopharyngeal level was found after the 7th day of sickness in one German study [54], after the 9th day in two American studies [56, 57] and after the 11th day according to data from Singapore [58]. It seems that there is consequently no risk of contagion 10 days after the symptoms first appear, even in the event of persistently positive PCR for SARS-CoV-2 [59, 60].

During the global spread of SARS-CoV-2, the genetic variants of the viruses emerged, and some have been proven to be more transmissible or could escape from host immunity, which posed an increased risk to global public health [61-63]. The viral loads in Delta infections are 1000 times higher than those in the earlier strain of infections. The window from exposure to the detection of the Delta variant peaks at 3.7 days and presented a higher infectiousness/transmission risk. The greater infectiousness of the Delta variant infections in asymptomatic individuals and in the pre-symptomatic phase highlights the need of timely quarantine for the suspicious infection cases or close contacts before the clinical onset or the PCR screening [64]. Symptom screening may also miss infectious people attending for tests.

Some patients after COVID-19 disease, especially those with pneumonia, may require LFTs to explain persisting symptoms. The major concern is the long-term consequences of the disease. Based on still limited information, a consensus approach prior to LFTs would be to include the following options. Pre-test screening for performing LFTs in post-COVID-19 patients is based on the supporting evidence at this time, e.g. CDC description of illness severity [65]:

- No earlier than 10 days after onset of symptoms in mild-to-moderate COVID-19 patients with two negative PCR tests after disease.

- No earlier than 20 days after symptom onset in severe COVID-19 patients with a negative PCR test.

- $\quad$ No earlier than 30 days after symptom onset and no PCR test needed. 
- Immunocompromised patients should be consulted individually, and two negative PCR tests are recommended

Section 3: Operational issues and environment

a) Appointment procedures

The appointment procedure must specify that the patient arrives no more than a few minutes before the scheduled time to avoid the aggregation of people in the waiting area. Remind the patient that they must arrive wearing a face cover. Inform the patient of the pre-screening procedure and ask the patient to attend alone except for specific populations requiring support (e.g. caregiver, translator/interpreter) (see Section 7 Testing outside the hospital). Consider the vulnerability of the patient and prioritise scheduling for the first appointment of the day, avoid the waiting room and receive them directly to the testing room or provide a dedicated waiting area. Include extra time between patients to allow the correct cleaning process, ensure adequate ventilation of the testing room, and donning and doffing according to the level of PPE required (see table 1) [65].

\section{b) Number of staff and patients per area (size and space), physical distancing}

Adequate physical distancing must be accommodated for in the area. Depending on the number of rooms available and on how many lung function professionals are working, the maximum number of patients in the area will be the number of patients being tested in specific rooms and the number of patients able to wait to be tested in the waiting room while respecting physical distancing. The WHO advises physical distancing of 3 feet $(\sim 1 \mathrm{~m})$, but the CDC of the USA mentions 6 feet $(\sim 2 \mathrm{~m})$, so recommendations differ from country to country. Therefore a minimum of 1 to $2 \mathrm{~m}$ between two persons not belonging to the same "family" (also defined as persons living under the same roof) should be considered. More recent publications have advised that activities such as coughing or shouting can spread SARS-CoV-2 $>2 \mathrm{~m}$ and that rules on distancing should reflect the multiple factors that affect risk, including ventilation, occupancy and exposure time [66]. Physical distancing must be respected during the patient appointment visit. To respect physical distancing, extra space must be allotted to the waiting area. If space is constrained, patients can wait in another area of the hospital (or in their cars if necessary) and be contacted when their testing can begin.

Physical distancing during test supervision and instruction is important. Performing lung function measurement often requires the physiologists to be within $<1 \mathrm{~m}$ of the patient for a prolonged period, thus use of appropriate PPE (as per table 1), adequate ventilation and regular equipment surface cleaning between patient appointments as per local institutional recommendations must be applied. Other important considerations are the vaccination rate and the local prevalence of different variants of the virus, and this may require more stringent infection protection strategies as data emerges.

\section{c) Waiting area}

Patients must wear a face mask at all times while they are in the waiting room. On arrival, patients must sanitise hands. Seats can be rearranged for physical spacing or, if not movable, they should be clearly labelled as seats that can be used or must be left empty. If unidirectional patient flow is possible, signs ( $e$. $g$. arrows on the floor) must be used to guide the patients. Waiting areas must be ventilated and general air-conditioning rules apply.

d) Staff rooms

Staff must wear a surgical face mask when occupying the same room. The type of mask used and maximum number of staff for that area should be risk assessed as per local hospital policy. Physical distancing must be maintained at all times, possibly by staggering working and break time arrangements. Rooms must be ventilated, and general air-conditioning rules apply. Rooms used for staff breaks such as eating lunch must be designated for this purpose with the space strictly adhering to physical distancing rules. Designated separate staff and patient toilet facilities are recommended.

\section{Section 4: Testing room precautions}

a) Air-conditioning and ventilation

SARS-CoV-2 particles can remain infectious in aerosol and droplet nuclei. Droplet nuclei are the residuals of dried droplets and aerosol particles of $\sim 1$ to $5 \mu \mathrm{m}$ in size [67]. They can potentially contain viable virus, remain suspended indefinitely in air and are transported over long distances [45]. The duration of infectivity depends on temperature and humidity [68, 69]. The exact factors determining the airborne distribution of infective SARS-CoV-2 particles are as yet unknown. However, an assumed requirement for airborne transmission is the presence of a source subject, patient or lung function staff who is in the early stages of infection and who is shedding viral particles into the air. Room ventilation helps to remove 
aerosol particles and airborne droplet nuclei. The majority of SARS-CoV-2 airborne transmissions have occurred in indoor environments [70], and at least one study has demonstrated the significant role of room ventilation in mitigating the airborne transmission of SARS-CoV-1 [71]. Although there have been no studies reporting an outbreak of SARS-CoV-2 in lung function laboratories, the potential risk of airborne transmission of the disease exists and may be enhanced by the performance of maximal or forced respiratory manoeuvres [72], including in pre-symptomatic patients if appropriate infection control practices are not followed. Appropriate heating, ventilation and air-conditioning (HVAC) systems are therefore an essential component of the prevention of the airborne spread of SARS-CoV-2 in addition to isolation measures, in lung function laboratories.

In centralised HVAC systems, air enters through an inlet, is filtered to remove particulate pollutants and micro-organisms, is conditioned to appropriate temperature and humidity levels, and is delivered to each room. A return duct system removes the air and delivers it back to the HVAC system. Depending on the settings of the system, a fraction of the returned air is filtered to remove contaminants, mixed with fresh filtered outdoor air and recirculated, with the exception of soiled or contaminated zones where all of the return air is exhausted to the outside [45]. During SARS-CoV-2 episodes, it is recommended to avoid central recirculation [68].

\section{b) Air exchange rates \& negative pressure rooms}

The pressure inside the laboratory room remains equal to atmospheric pressure, as long as the flow of delivered and returned air are equal. In healthcare facilities, ventilation is expressed as air changes per hour $(\mathrm{ACH})$, defined as the returned airflow divided by the room volume multiplied by 60 . Increasing $\mathrm{ACH}$ improves the efficiency of removing airborne particles. Another important parameter in preventing the airborne transmission of diseases is the time interval between two patient tests directly depends on ACH. Currently, there are no evidence-based recommendations for ACH in lung function laboratories specifically regarding the prevention of airborne transmission of SARS-CoV-2. The American Thoracic Society Pulmonary Function Laboratory Management and Procedure Manual [73] recommends ventilation rates of at least $6 \mathrm{ACH}$ for the prevention of mycobacterium tuberculosis (TB) transmission. However, peak efficiency for particle removal occurs between 12 and $15 \mathrm{ACH}$ [74, 75]. In many healthcare facilities, such rates of $\mathrm{ACH}$ may not be achieved. In this case, an adequate time required for airborne-contaminant removal should be allowed between two patients. A table showing the time required for contaminant removal as a function of ACH is available from the CDC (table 3) [76]. In March 2021 the WHO published a roadmap to improve and ensure good indoor ventilation in the context of COVID-19 and healthcare setting [77].

\section{c) HEPA units}

Centralised HVAC systems that cannot provide adequate air removal can be augmented with portable, industrial-grade HEPA units [78]. Portable HEPA-filtered ventilation may be effective against aerosols that travel both long distances as well as short ranges [71]. Experimental and computational fluid dynamics studies suggest that when coupled with localised exhaust devices, such portable ventilation units can further enhance the overall ability to mitigate exposure in healthcare settings [78]. However, there are no known epidemiological studies that demonstrate a reduction in infectious disease transmission. In lung function laboratories inside large healthcare facilities with central HVAC units, windows should ideally be sealed to reduce the risk of airborne contamination from the outside [79]. In smaller healthcare facilities and offices, when air change rates are insufficient, opening windows can contribute to indoor air renewal when tests are not being performed. However, opening windows exposes to the risk of contamination from the outside, ensures variable rates of air exchange, can significantly disrupt indoor laboratory temperature and humidity control, and may require recalibration of body plethysmographs once the time interval between patient examinations is over. Finally, central HVAC systems should be regularly monitored and maintained as per national and institutional standards and guidelines, to ensure adequate ventilation $\mathrm{ACH}$ and indoor air quality.

\section{d) Plexiglass barrier/shield and equipment covers}

Maintaining a physical distance of $2 \mathrm{~m}$ from the patient and use of physical barriers can potentially help protect direct droplet transmission and augment the safety of healthcare workers [80]. Although droplets from a coughing patient might not directly reach the person on the other side of the screen, it will not prevent the transmission of airborne pathogens via aerosols. The use of these low-cost barriers (see figure 3) might increase the safety perception of patients and healthcare workers and is already widely applied outside the hospital setting (e.g. in shops, at counters and elsewhere), especially if other safety options are not available. The barriers will not help where a patient requires special assistance where physical 

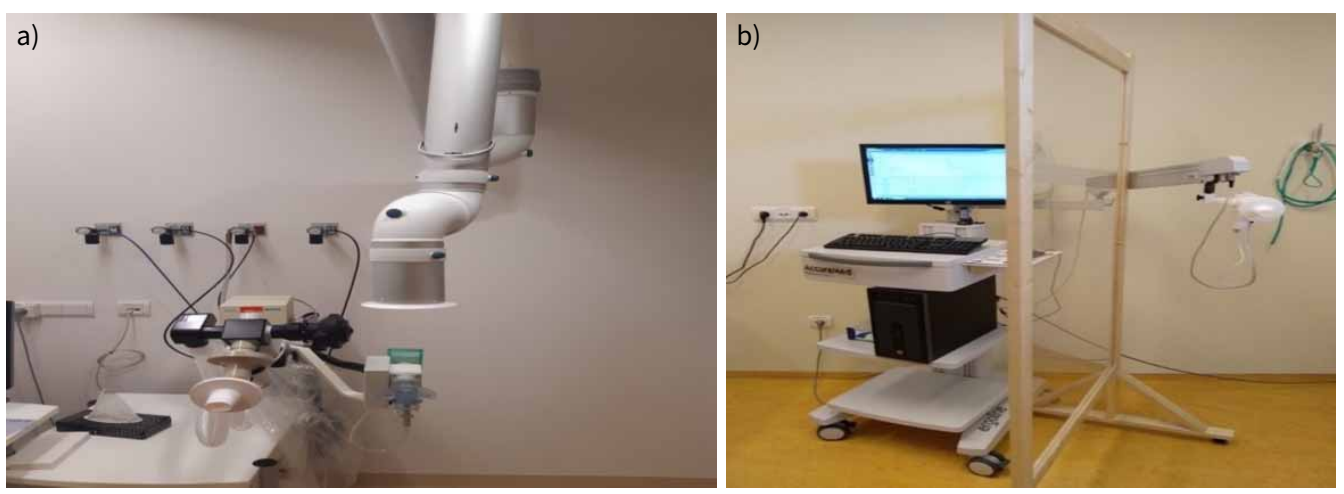

FIGURE 3 a) An extraction hood positioned immediately over the dosimeter/nebuliser. b) Large protective screen on casters, separating patient from staff, providing some droplet protection if the patient coughs.

distancing is impossible. The use of disposable covers for the testing equipment has been recommended to avoid equipment contamination by aerosol transmission on the proximal side of the exhalation port [27].

\section{e) Use of body plethysmographs as isolation chambers}

Some professional societies recommend that spirometry be performed inside the closed body plethysmograph [81]. Potential environmental contamination occurs when the patient disconnects from the filtered mouthpiece and/or coughs. This option may provide a barrier and contains the droplets and aerosols generated within the cabin of the box; however, it is advisable to consult with equipment providers on how this may impact on measurements. Thorough ventilation and decontamination of the cabin between patients are essential, and replacement of the sensor is often advisable depending on the equipment design.

Section 5: Lung function test procedures during COVID-19 pandemic

Group consensus on general approaches for consideration when performing LFTS

All of the following approaches apply to sections 5.1a to 5.1k:

- Follow WHO advice on effective hand hygiene and patient compliance with cough etiquette.

- Utilise effective ventilation strategies to maximise the removal of infective micro-organisms and minimise downtime (droplet pause) between patients.

- Maintain physical distance $>1$ to $2 \mathrm{~m}$ if at all possible.

- Use of physical barriers (Perspex/plexiglass) may provide added protection from droplet exposure.

- $\quad$ Refer to table 1 for PPE and disposable test filter requirements.

- Minimise exposure time with a patient, especially where $>1 \mathrm{~m}$ distance cannot be maintained and room ventilation is inadequate.

- Patients capable of replacing their face masks between test efforts must be encouraged to do so, but this may not always be possible.

- Always clean the external surfaces of equipment and the test area after the droplet pause, and between each patient test.

- Rooms must have adequate clean air ventilation while ensuring adequate temperature control for normal functioning of lung function equipment.

The following additional approaches apply to sections 5.1j Cardiopulmonary exercise test and $5.1 \mathrm{k}$ Bronchial challenge testing:

- Vigilant pre-test screening of patients and the use of appropriate PPE as per table 1.

- Consider pre-visit RT-PCR test when screening.

- We discourage the use of re-circulating air-conditioning units and fans, as these will likely extend the time potential infective contaminants remain airborne.

- Air-conditioning system can only be used if it does not allow the internal recirculation of air or has some inherent HEPA/UV cleaning capabilities.

- Negative pressure rooms or knowing the number of ACH within the testing facility will allow more precise waiting times to be set.

- Testing facilities should be closed off to personnel for a minimum period of settling time to allow airborne droplets to settle on surfaces. Surfaces may then be cleaned with appropriate cleaning solutions or via UV cleaning. 


\subsection{Specific tests \\ a) Spirometry}

Spirometry has an increased risk of transmitting viruses through droplets and aerosol generation. This test commonly induces a cough and may produce droplets carrying SARS-CoV-2 in an infected person even if he or she is asymptomatic. Normal breathing during spirometry has recently been reported to generate aerosol-sized particles. Researchers detected particles generated close to the exhalation port warranting the use of single-use plastic covers over exposed equipment parts, and the size of the particles generated warrant the use of N95 masks and PPE during routine spirometry [1]. They also advised the importance of maintaining physical distance from the patient, room air exchange and room turnaround time between patients. Another research study showed that small droplet emission varies for different breathing manoeuvres performed during LFTs, with very low production during tidal breathing and much higher yields during cough and vital capacity post inspiration. The data suggest that the first few breaths immediately following the vital capacity measurement should be exhaled into a filter before coming off the mouthpiece, ensuring particles are all exhaled into filters [27].

Consensus: Spirometry tests must be carried out using a high-efficiency inline filter. The risk is only reduced while the patient remains breathing on the mouthpiece. End all spirometry manoeuvres with two to three tidal breaths before instruction to remove themselves from the mouthpiece. The patient must be advised to replace their face mask without delay between trials. Protective covers can be used to reduce contact transmission. Refer to figures 2 and 3 for more information.

\section{b) Drug delivery as part of bronchodilator response testing}

Airway delivery of bronchodilators to assess bronchodilator response is a common procedure, and various techniques are used. Most commonly, bronchodilators are delivered with pressured metered-dose inhalers (pMDI) with or without additional spacers or valved chambers. Current ERS guidelines recommend the pMDI and valved chamber combination. Although this equipment is designed for single-patient use, many reuse a common canister which is cleaned and disinfected between patients. During the pandemic cleaning and disinfection of mouthpieces, spacers and chambers are critical for infection control. Although the generation of patient-derived bioaerosols during pMDI use has not been directly explored, indirect evidence supports this concept. In healthy subjects, a single deep inspiration (as performed when using a metered-dose inhaler) followed by deep exhalation leads to a four-fold increase in the number of exhaled bio-aerosol particles originating from distal airways [82]. Thus, pMDI delivery may not be considered a low-risk procedure for healthcare workers, and it is suggested that staff be equipped with appropriate PPE when SARS-Cov2 community transmission is prevalent.

Alternatively, dry powder inhalers (DPI) or nebulisers may be used. Depending on the technique used, contamination of the environment can occur especially for nebulised drugs where the aerosol can be delivered directly to the environment and indirectly by exhalation of aerosol that was inhaled but did not deposit in the airways. Importantly, inhaled drug delivery may also be related to contamination of the environment with bioaerosols that originate from the patient and carry infective potential. SARS-CoV-2 has been reported to be viable for at least $3 \mathrm{~h}$ following nebulisation using a jet nebuliser [83].

Consensus: Use of valved chambers/spacers with a pMDI is preferable to nebulisers for bronchodilator administration as part of reversibility testing during high prevalence. Careful and rigorous decontamination of all reused equipment is advised.

\section{c) Lung volumes/body plethysmography}

There are several methods of measuring static lung volumes including multiple breath gas washout/dilution systems or body plethysmography systems. Most gas washout/dilution systems, like Helium dilution technique, Oxygen, Nitrogen, or SF6 wash-in/washout technique are performed with a bacterial/viral filter in place. The measurement requires normal breathing and mostly passive manoeuvres. In the case of body plethysmography, the patient is sitting in a closed environment (non-ventilated) box. There are periods between measurements where the patient is not breathing on the filter/mouthpiece so breathing unfiltered inside of the box.

Consensus: Use a high-efficiency inline filter when performing any lung volumes testing. End all vital capacity manoeuvres with two to three tidal breaths before removing the mouthpiece. The body plethysmograph can be contaminated and must be cleaned carefully and appropriately while wearing PPE. 


\section{d) Diffusing capacity/transfer factor}

The gold standard test is the diffusing capacity by a single breath technique. This test involves the inhalation, breath-hold and exhalation of special mixed gas. It does not necessarily require a forced effort; however, sometimes patients can cough if the inhalation of the test gas is too fast.

Consensus: Use a high-efficiency inline filter when performing the diffusing capacity test. End all vital capacity manoeuvres with two to three tidal breaths before removing the mouthpiece.

\section{e) Exhaled nitric oxide tests}

\section{Exhaled nitric oxide}

Measurement of exhaled nitric oxide $\left(F_{\mathrm{ENO}}\right)$ requires an exhalation against a resistance while breathing through a viral/bacterial filter. To measure bronchial production of NO, the patient inhales up to total lung capacity, then exhales at a $50 \pm 5 \mathrm{~mL} \cdot \mathrm{s}^{-1}$ flow. This manoeuvre does not require a forced or a maximal expiratory effort.

Consensus: Use an inline filter when performing this test.

Nasal NO

All methods of testing involve air sampling in one of the nostrils via an olive insert with the other nostril free of any obstruction. A microbial filter must be placed between the olive and the sampling line or the sampling line must be discarded/disposed after each patient. The recommended respiratory manoeuvre performed during nasal NO measurement involves an exhalation against a resistance, while keeping the soft palate closed.

When the patient exhales against a resistance into the NO analyser, the manoeuvre is similar to that of $F_{\text {ENO }}$ measurement (inline filter). When the patient exhales outside the NO analyser (independent resistance) or performs alternative respiratory manoeuvres (breath holding, tidal breathing), the expiration is performed without a filter.

Consensus: An in-circuit (sampling line) filter must be used for this test. If it is not possible to use a filter, the circuit must be discarded. If exhalation does not occur through a filter, it is important to maintain physical distance and minimise exposure time.

\section{f) Oscillometric assessment of respiratory mechanics}

Oscillometry, also called forced oscillation technique (FOT), consists of the application of an external oscillatory pressure signal superimposed on spontaneous breathing, while measuring the resulting flow and pressure response of the respiratory system. The technique allows measuring respiratory input impedance at multiple frequencies. Although referred to as "forced oscillation", this technique is a tidal breathing method and does not require forced respiratory manoeuvres.

Consensus: Use a high-efficiency inline filter when performing this test.

\section{g) Capnography}

Capnography is defined as the non-invasive measurement of the partial pressure of carbon dioxide $\left(\mathrm{CO}_{2}\right)$ in exhaled breath and is expressed as the $\mathrm{CO}_{2}$ concentration over time. Although capnographs are used to measure $\mathrm{CO}_{2}$ during spontaneous breathing and/or normal ventilation, they can also be subject to high flows (e.g. during coughing or hyperventilation of a patient).

Consensus: An appropriate in-circuit filter must be used

\section{h) Respiratory muscle pressures/sniff test}

These tests require maximal inspiratory and expiratory mouth or nasal pressure measurement. These manoeuvres can also induce coughing afterwards, since pulmonary stretch receptors are triggered. During 
the test, there is an increased risk of air leakage at the mouthpiece. A flanged mouthpiece is typically used; however, an inline bacterial/viral filter must be used to prevent cross-contamination.

Consensus: A flanged mouthpiece is typically used; however an inline bacterial/viral filter must be used to prevent cross-contamination.

The sniff measurement cannot be performed with a nasal filter, and one nostril remains open, thereby opening up a pathway for aerosol spreading.

Consensus: Use disposable nasal olive and tubing. Maintain physical distance and minimise exposure time.

\section{i) 6-min walk test}

The 6-min walk test (6MWT) requires a submaximal level of exertion, and sometimes, in patients with chronic respiratory failure, a maximal level of exertion. The best measure to decrease transmission is by using a face mask [84]. The impact of wearing a face mask when walking has been evaluated in both patients and healthy subjects. Wearing a surgical mask does not reduce the distance covered in a 6MWT but alters the sensation of breathing effort in healthy subjects. The performance of a 6MWT in patients with active SARS-CoV-2 infection should be duly justified given the risk of interpersonal transmission.

\section{Consensus:}

The corridor must be low traffic and have natural ventilation.

The patient must wear a surgical mask during the entire test.

- For patients who cannot tolerate a surgical mask (due to severe lung disease), an alternative option is a plastic face visor; however, extra precautions must be taken to protect staff, i.e. extra PPE must be worn by staff conducting the test.

\section{j) Cardiopulmonary exercise tests}

Cardiopulmonary exercise testing (CPET) is an important tool in the identification of differential diagnosis, response to interventions and risk stratification for surgical procedures. Resting assessments poorly identify exercise-associated pathophysiology and so the delivery of CPET services is essential. However, these services must be delivered safely for both the patient performing the test and the staff coaching the patient. During CPET the patient is breathing at ever increasing ventilation rates without the exhaled breath being filtered. The potential, therefore, to produce infected droplets will increase the risk of both airborne and surface transmission and needs consideration regarding the potential for protracted viral shedding (i.e. the test lasts $>10 \mathrm{~min}$ ). Appropriate mitigation strategies are required to ensure that CPET can be conducted safely and without posing a risk of transmission and infection. The use of bacterial/viral filters that are routinely used in other LFTs have been postulated as a potential option to further mitigate risk associated with CPET. These filters have an inherent resistance to exhalation and inhalation, but this is very low in relation to the expiratory and inspiratory flows. At high ventilation associated with maximal exercise the likely resistance is still relatively low and would be unlikely to impact exercise performance. The issue associated with the use of such filters on exercise is the water vapour in the exhaled breath which will likely saturate the filter as the exercise test ensues, thus leading to increased resistance to ventilation and impacting exercise performance and dyspnoea, especially in patients with anomalies in ventilatory mechanics. A PhD thesis from 2012 [85] outlined a trend towards significance of the increase in ventilation at peak exercise in the presence of a filter, but this aspect needs to be verified and validated in further larger studies involving patients and not only healthy volunteers. More recently researchers have confirmed the deleterious effects of using filters during CPET and the impact on measurements and interpretation of results [86]. We therefore advise extreme caution when considering the use of bacterial/ viral filters manufactured specifically for lung function testing as filter exhalation during a CPET.

Consensus: Single-use masks, sensors, turbines and gas lines should be used to prevent transmission from the repeated use. See introductory consensus notes 5.1a to 5.1k.

\section{k) Bronchial challenge tests}

Measures to avoid cross contamination during inhaled drug delivery in the LFT setting For a variety of reasons, doing a bronchial challenge test (BCT) on someone who might have COVID-19 would have to be 
considered a high transmission risk. Thus, as in all medical interventions, this risk must be considered in relation to the benefit to be gained from BCT in each patient. Basic pre-test screening for COVID-19 exposure or symptoms, as appropriate for any current lung function service encounter, should be done and, if available, coronavirus testing would be desirable. In a patient known to be COVID-19 positive, the risk of transmission would be greatly elevated and the benefit of the test reduced because respiratory viral infections may cause a positive BCT, so there would be little point in proceeding. Risks of respiratory disease transmission during testing can be mitigated slightly by equipment choices but will depend on appropriate PPE and adequate room ventilation.

Where possible communication exists between the airway opening, either mouth or nose, and the reservoir of a jet nebuliser, due to drooling or just secretions from the mouth or nose, if the subject has COVID-19, the reservoir must be considered contaminated. Hence any aerosol generated will contain infective particles. During the SARS epidemic in 2002/2003, an outbreak in a crowded ward in Hong Kong was linked to jet nebuliser use. This was almost certainly due to the nebulisation from a contaminated reservoir of the nebuliser and the close proximity of the other patients. This risk can be mitigated to some extent with the use of a vibrating mesh nebuliser where the reservoir will not come in contact with any patient secretions [87], but high-quality filters on the expiratory limb of the nebuliser setup should be considered mandatory.

Another issue is that many subjects cough when performing the test. This usually means taking the nebuliser out of their mouths so that aerosol can enter the environment rather than passing through the filter on the expiratory limb of the equipment. Hence both infected droplets from the coughing subject or from the contaminated reservoir may enter the environment. Nebulisers with a contaminated reservoir that continuously produce aerosol during both the expiratory and inspiratory phase will nebulise directly into the environment if removed from the mouth. Breath-activated nebulisers that cease nebulisation when there is no inspiratory flow through them may offer some advantage. The aerosol that entered but did not yet deposit in the anatomical dead space of the subject or the device will be expired into the atmosphere. While breath-activated nebulisers will reduce the amount of aerosol emitted during the expiratory phase, it is not reduced to zero [88].

It is becoming recognised that COVID-19 virus particles are infectious not only as droplets, but also in the airborne phase analogous to that of other diseases such as tuberculosis. There are good data to suggest that droplets of $5 \mu \mathrm{m}$ or less are likely to penetrate below the vocal cords if inhaled, and most nebulisers are designed to produce an aerosol with this particle size. Hence, small, contaminated droplets will be released into the environment and, if still infective after the aqueous carrier has evaporated, will remain as a hazardous suspension for a significant period of time. This would imply that the ventilation standards currently in place for the prevention of the spread of diseases such as tuberculosis or measles would be required during a bronchial provocation test. At the very least for PPE, this would require the equivalent of an N95 tight-fitting mask and face protection to prevent droplet spread to the eyes of the staff. Even more protection would be given by a positive pressure hood such as is the case for those doing bronchoscopy with subjects with a suspicion of tuberculosis.

Consensus: Use breath-actuated nebulisers with single-use filters on the expiratory port of the nebuliser (see introductory consensus notes Section 5.1a to 5.1k).

Mannitol challenge and other bronchial challenge tests

Mannitol may cause significant cough and/or throat irritation in some individuals [89]. Cough is a common side-effect of mannitol challenge tests possibly due to the combination of the low-resistance device, and a high inspiratory flow, and can result in cough through a mechanical cough reflex due to oropharyngeal deposition of the mannitol [90]. In a phase III study investigating the safety and efficacy of inhaled mannitol as a bronchial challenge test, cough occurred in 535 of 592 (of whom 91 were non-asthmatic) subjects. In some cases, cough was so severe that the test had to be delayed (one in seven subjects), or even ended prematurely (1 in 100 subjects). Therefore, this test has a high risk of virus transmission, and should be managed as a higher risk AGP and conducted only in a ventilation-controlled room. PPE as per table 1 should be used.

Exercise provocation, eucapnic voluntary ventilation $(\mathrm{EVH})$ and cold air challenge tests require strong stimulus test targets such as high ventilation rates to induce bronchoconstriction [91]. The stimulus is also delivered continuously over several minutes. There is currently no reported evidence on the use or impact of filters during these tests. A common side-effect of these tests is cough due to the osmotic changes 
induced by the strong stimulus applied. There is also a high chance of hypersalivation and environmental contamination with EVH and cold air tests. Consequently, these tests have a high risk of virus transmission, should be managed as an AGP and conducted only in a ventilation-controlled room. PPE as per table 1 (BCT) should be used. Cough, which is commonly associated with inhalation of bronchoconstrictor agents, may also contribute to bio-aerosol generation. Therefore, airway drug delivery carries the risk of exposure to patient-derived bioaerosols and thus carries a risk of infection for healthcare workers.

Consensus: See introductory consensus notes $5.1 \mathrm{a}$ to $5.1 \mathrm{k}$.

\subsection{Filters}

a) Lung function test filters

Selecting the appropriate filter requires conformance with several different criteria including type, efficiency, cost, performance, impact on dead space and calibration [91]. The filter manufacturer must provide written documentation of this information ideally with independently verified test data. International and national guidelines suggest that the resistance of the circuitry of an instrument including the filter should be $<0.15 \mathrm{kPa} \cdot \mathrm{L}^{-1} \cdot \mathrm{s}^{-1}$ [92]. The final consideration when deciding on the appropriate filter type is the size of the particle that is trapped by the membrane. Knowledge of the magnitude of airborne pathogens in comparison to other particles that may be inhaled from the air can be related to the grade of filter that is necessary for the protection of equipment from a pathogen. In lung function systems, the filter with a total circuit resistance that complies with international and national standards and provides the greatest protection should be used. Equipment calibration must be carried out with the filter in place [93].

\section{Filtration efficiency related to spirometry filters' membrane}

Front-end filters Single-use bacterial/viral inline filters that meet international standards of filtration performance should be used for each patient [94]. Filters must have been tested with viral-sized particles that are smaller than SARS-CoV-2, i.e. $<0.8 \mu \mathrm{m}$. Given that high peak expiratory flows in the range of 400 to $700 \mathrm{~L} \cdot \mathrm{min}^{-1}$ are generated by adult patients during spirometry, filters must have been tested at a continuous high expiratory flow for a period of time to demonstrate a minimum proven viral filtration efficiency of at least $99.9 \%$ to reduce at minimum the "cross-contamination" risk. Some filter manufacturers have tested their filters for between $2 \mathrm{~min}$ and $5 \mathrm{~min}$, and this type of information can be provided by the manufacturers. Each laboratory should confirm with manufacturers that filters adequately protect against SARS-CoV-2-sized viral particles.

\section{b) Nebuliser and dosimeter filters for methacholine challenge tests}

Back-end filters The specification of the high-efficiency filters is important, e.g. compliance with $\mathrm{NaCl}$ filtration standard ISO 23328-1, bacterial and viral filtration efficiency, pressure/flow resistance and water retention. Filter efficiency should be checked for both dry and wet conditions. Flow resistance must be based on ISO 9360-1:2000 and water retention. Note that most currently used filters are tested with salt aerosol at a penetrating aerosol size of $\sim 0.3 \mu \mathrm{m}$ and a flow of $30 \mathrm{~L} \cdot \mathrm{min}^{-1}$, and a range of different particle sized aerosols consistent with SARS-CoV-2.

Section 6: Management of special populations

Many attending for tests are often vulnerable patients who require special consideration and/or urgent evaluation. Infection prevention and control is crucial for all patients but especially for particular patient groups. These patients are often accompanied by other persons (parent, caregiver or interpreter). Accompanying persons/chaperones must also undergo triage if they are required to enter the testing area, wear face masks and comply with physical distancing rules. When a patient is undergoing advanced tests such as CPET and bronchial challenge tests, accompanying persons must also wear appropriate PPE and comply strictly with physical distancing. A risk assessment may also be required.

\section{a) Paediatrics}

A paper published by an international expert paediatric group [95] discusses the particular precautions commonly used in paediatric lung function services. They provide detail specific to paediatrics on test preparation, testing rooms, LFT procedures, and aerosol generation, testing personnel, tidal breathing techniques, proposed long-term changes to practice, test indications, considerations for specific patient groups, e.g. patients with cystic fibrosis (CF), home testing for CF patients and directions for the future. 


\section{b) Elderly patients}

Patients aged over 65 years have been identified in the high risk of severe and critical course of COVID-19 group, some burdened by comorbidities. The case-fatality rate due to COVID-19 is significantly higher than in the general population [96, 97]. Thus, lung function testing in elderly individuals should be assessed carefully. The urgent/essential clinical circumstances for lung function testing need to be discussed with the clinician in terms of benefit/risk balance and if so, performed with extreme precautions.

\section{c) Lung cancer and surgery patients}

Lung function services have mostly continued for cancer diagnosis and therapy/surgery. Although in the first wave, fewer patients presented to their primary care doctors with suspicious symptoms related to cancer, patients are encouraged to seek treatment as the hospitals have restarted services in the safest manner possible. Patients attending for LFTs are prioritised and extra precautions are followed dependent on the patient circumstances.

\section{d) Immunocompromised patients}

Special considerations must be given to patients with compromised immune systems. Prioritise patients who urgently require testing to the first appointment of the day; use of a separate waiting area or taking patients directly to the testing rooms is advisable. An assessment of risk to the patient may be necessary and consideration of alternative testing options be considered (see figure 2).

\section{e) Post-COVID-19 rehabilitation}

Lung function is an important part of patient evaluation in post-COVID-19 disease [98]. Studies to optimise rehabilitation might require serial lung function measurements. Priority must be given to this patient group based on post-infection wait times for LFTs as discussed in Section 2c.

\section{Section 7: Testing outside the hospital}

\section{Spirometry in the community and primary care}

Spirometry is the most common lung function test performed in the community (e.g. primary care, occupational health) and carries the same risks as hospital-based spirometry (indoor testing). There are some important factors to consider:

- In the past, the use of disposable flow sensors has been considered a very safe way of testing; however, now the risk of potential contamination through the expiratory airflow is high. Some manufacturers have developed a filter solution in response to the requirement, and where available they must be used.

- In the community setting the testing rooms are not often a suitable size or equipped with an adequate ventilation system. Until there is a clear understanding of the infective transmissibility of SARS-CoV-2, we endorse a precautionary approach and to follow the many national or institutional recommendations of indoor testing and requirements for PPE and room ventilation.

- If spirometry cannot be performed for the reasons mentioned above, the patient might have to be referred to the hospital laboratories with the necessary facilities.

- Another option to consider is "in-car" spirometry, similar to in-car COVID-19 PCR testing. This outdoor testing approach was introduced in the UK for the continuity of spirometry services [49]. Many patients express a fear of attending the hospital for tests, and this offers the patients an option to be tested in their own car, where they may feel safer. This option has its difficulties, e.g. obtaining accurate height measurement, and establishing whether the car seat offers the correct sitting position, and it is weather dependent. Positives are that it allows for continuity of service, no restrictions on physical distance from the patient during testing and does not impact on hospital accommodation.

\section{Section 8: Telemedicine/video-coached spirometry}

The traditional practice of medicine around the world was transformed due to COVID-19, and public and private providers were forced to rapidly adapt and continue to deliver care using innovative solutions. LFTs are not exempt from this trend; in fact several spirometer companies were already prepared and had products ready to offer to the telemedicine market. Some of them are specifically designed for connected health applications with other sensors and applications, such as oxygen saturation measured by pulse oximetry $\left(S_{\mathrm{pO}_{2}}\right)$, ECG and 6MWT. Since telemedicine allows lung function measurements (with or without video instruction) at home, this is a safe application to prevent the spread of the virus, but it requires trained patients, sufficient devices and a safe platform for immediate and continuous updates to the clinician about lung health trends. Although this option has proved helpful during the peak phases of the pandemic, it was demonstrated in a recent study that telemedicine home tests of vital capacity were poorly correlated to lab-based measurements thus should not be used as a permanent replacement for performing LFTs [99]. 


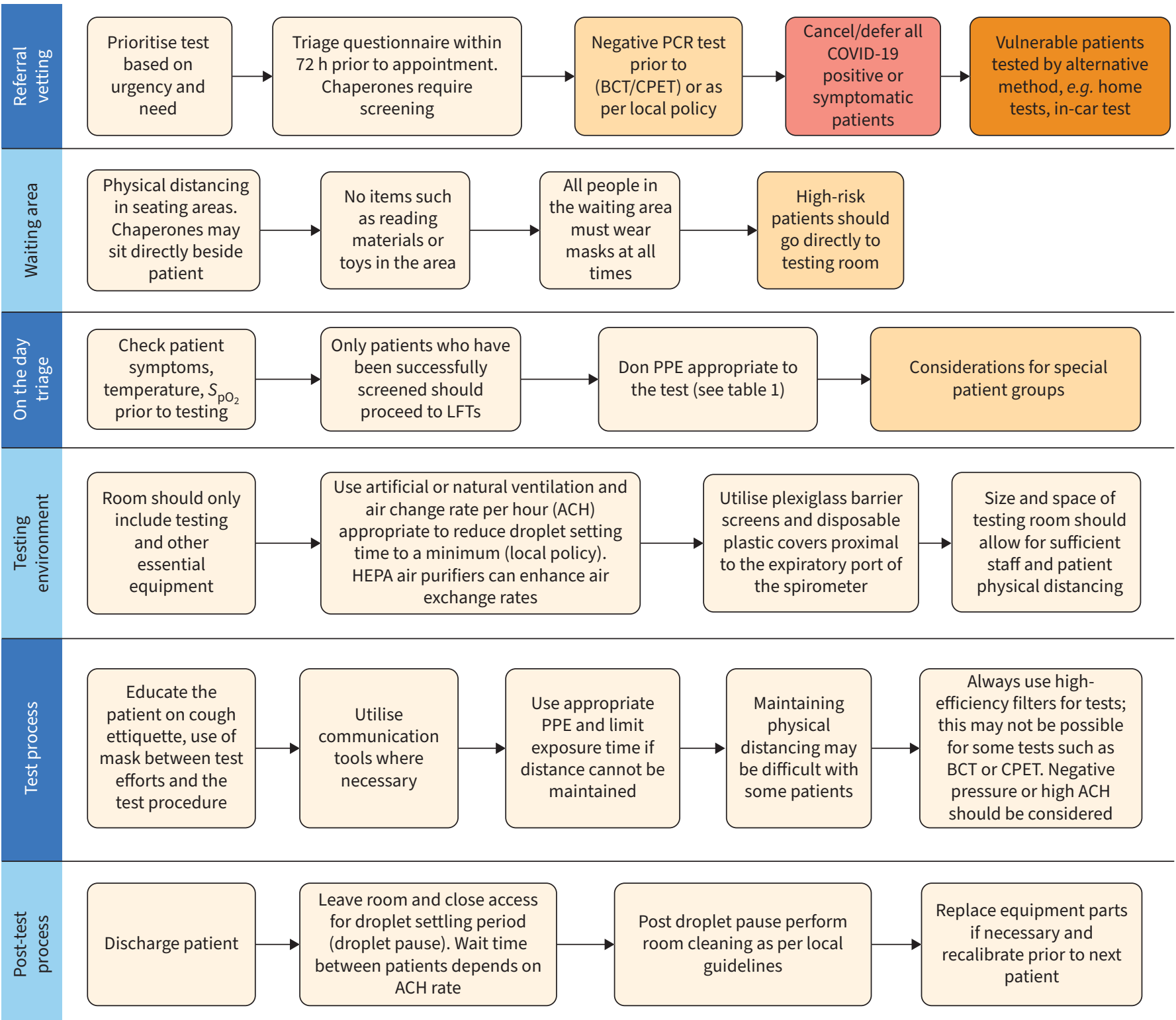

FIGURE 4 Lung function testing (LFT) pathway with precautions during coronavirus disease 2019 (COVID-19) pandemic. BCT: bronchial challenge test; $\mathrm{CPET}$ : cardiopulmonary exercise testing; $\mathrm{S}_{\mathrm{PO}_{2}}$ : oxygen saturation measured by pulse oximetry; PPE: personal protective equipment; $\mathrm{HEPA}$ : high-efficiency particulate air; $\mathrm{ACH}$ : air changes per hour.

\section{Section 9: Patient information}

The European Lung Foundation (ELF) stresses the need that patients continue to have their health needs met as before the COVID-19 pandemic [100]. It is therefore of utmost importance that regular appointments can go on safely, or be rescheduled to a safer time, or take place via, for instance, telephone or video call. A hospital and the lung function laboratory must be safe environments for each patient so appropriate care can be delivered at all times.

\section{Section 10: Conclusion}

In this document, we have provided an expert group consensus on the performance of LFTs in the period of COVID-19. We anticipate this consensus may also be relevant for any future respiratory pandemic. We have presented an overview of operational and environmental issues. For individual tests, we have provided our consensus on specific test requirements, the PPE that is advised and how cleaning should be prioritised. 
This virus has highlighted how vulnerable a healthcare system is and forces us to re-think which tests are necessary under pandemic situations, and whether they are essential to patient care. If so, then how can tests be prioritised and safely performed while also ensuring the safety of the patient as well as the healthcare worker. In the past, hospitals were built to safely deal with a patient suffering from pulmonary disease such as tuberculosis, but the current situation shows that for COVID-19 patient management systems must be improved.

Lung function procedures might therefore be altered in the future to make them safer in preventing the transmission of disease via contact, droplet and also aerosol production and contamination. It might have far-reaching effects, for instance in the ventilation and filtering demands of hospital rooms and waiting areas, and also on cleaning procedures. A suggested pathway for LFTs with precaution is detailed in figure 4.

Provenance: Submitted article, peer reviewed.

Conflict of interest: A. McGowan has nothing to disclose. P. Laveneziana reports personal fees from Novartis France, Chiesi France and Boehringer France, outside the submitted work. S. Bayat has nothing to disclose. N. Beydon has nothing to disclose. P.W. Boros has nothing to disclose. F. Burgos reports participation on a scientific advisory board for Medical Graphics Coorporation Diagnostics. M. Fležar has nothing to disclose. M. Franczuk reports personal fees from AstraZeneca, Boehringer Ingelheim and Chiesi, outside the submitted work. M-A. Galarza has nothing to disclose. A.H. Kendrick has nothing to disclose. E. Lombardi reports nonfinancial support from AbbVie, personal fees from Angelini and Boehringer, personal fees and nonfinancial support from Chiesi, personal fees from GSK, nonfinancial support from Lusofarmaco, personal fees and nonfinancial support from Novartis, personal fees from Omron, grants and nonfinancial support from Restech, grants and personal fees from Sanofi, personal fees and nonfinancial support from Vertex, and personal fees from Vifor, outside the submitted work. J. Makonga-Braaksma has nothing to disclose. M.C. McCormack reports royalties from UpToDate, and personal fees from Vera Med, GlaxoSmithKline and Celgene, outside the submitted work. L. Plantier has nothing to disclose. S. Stanojevic has nothing to disclose. I. Steenbruggen has nothing to disclose. B. Thompson has nothing to disclose. A.L. Coates has nothing to disclose. J. Wanger has nothing to disclose. D.W. Cockcroft reports participation on a medical advisory board for Pharmaxis. B. Culver has nothing to disclose. K. Sylvester has nothing to disclose. F. de Jongh has nothing to disclose.

References

1 Helgeson SA, Lim KG, Lee AS, et al. Aerosol generation during spirometry. Ann Am Thorac Soc 2020; 17: 1637-1639.

2 Wilson, NM, Marks, GB, Eckhardt, A, et al. The effect of respiratory activity, non-invasive respiratory support and facemasks on aerosol generation and its relevance to COVID-19. Anaesthesia 2021; 76: 1465-1474.

3 McGowan A, Sylvester K, et al. Lung function testing during COVID-19 pandemic and beyond. Recommendation from ERS Group 9.1 [Respiratory function technologists/scientists] ERS Group 9.1, May 2020. https://ers.app.box.com/s/zs1uu88wy51monr0ewd990itoz4tsn2h

4 Thompson B, Warner J. Peak Respiratory Bodies recommend suspension of lung function testing. The Thoracic Society of Australia \& New Zealand and Australian and New Zealand Society of Respiratory Science Ltd, 2020. https://nwmphn.org.au/wp-content/uploads/2020/10/peak_respiratory_bodies_recommend_suspension_ of_lung_function_testing.pdf. Accessed June 2020

5 ARTP COVID-19 Group. Respiratory function testing during endemic COVID-19. www.artp.org.uk/write/ MediaUploads/Standards/COVID19/Respiratory_Function_Testing_During_Endemic_COVID_V1.5.pdf Date last updated: 26 May 2020.

6 Wilson KC, Kaminsky DA, Michaud G, et al. Restoring Pulmonary and Sleep Services as the COVID-19 Pandemic Lessens. From an Association of Pulmonary, Critical Care, and Sleep Division Directors and American Thoracic Society-coordinated Task Force. Ann Am Thorac Soc 2020; 17: 1343-1351.

7 Pulmonary Function and Clinical Respiratory Physiology Working Committee of Respiratory, Physicians Branch of Chinese Medical Doctor Association, Pulmonary Function Group of Respiratory Therapy Group, Respiratory Disease Branch of Chinese Medical Association. Expert consensus on lung function examination during the prevention and control of new coronavirus pneumonia. Chinese J Tuberculosis Respir Dis 2020; 133: 1595-1602.

8 Canadian Society of Respiratory Therapists. Position Statement on Procedures creating a heightened risk of infection during an outbreak of a communicable respiratory disease. CSRT 2020. www.csrt.com/wp-content/ uploads/CSRT-Procedures-Duringan-Outbreak-April-2020-v2.pdf

9 Bignamini E, Cazzato S, Cutrera R, et al. Italian pediatric respiratory society recommendations on pediatric pulmonary function testing during COVID-19 pandemic. Ital J Pediatr 2020; 46: 68. 

Pulmonary Function Units of the Different Care Settings. Spanish Society of Allergy and Clinical Immunology, 2020, p. 1-7. https://drive.google.com/file/d/1JPyCJ0 qiewcUTybJd0sxkruj-lbr8Z9/view.

11 Plantier L, Costes F. groupes de travail 'Fonction' et 'Alvéole' de la Société de pneumologie de langue française. Rev Mal Respir 2020; 37: 608-612.

12 Gemicioğlu B, Börekçi ş, Görek Dilektaşlı A, et al. Turkish Thoracic Society Experts Consensus Report: recommendations for pulmonary function tests during and after COVID 19 pandemic. Turk Thorac J 2020; 21: 193-200.

13 Lombardi C, Milanese M, Cottinin M. Rethinking Respiratory Function Test Lab in the Era of COVID-19: considerations about the "today" and the "day after". Ann Allergy Asthma Immunol 2020; 125: 210-211.

14 McCormack MC, Kaminsky DA. Pulmonary Function Laboratories: Advice Regarding COVID-19. www.thoracic. org/professionals/clinical-resources/disease-related-resources/pulmonary-function-laboratories.php Date last accessed: March 2021. Bhardwaj J, Hong S, Jang J, et al. Recent advancements in the measurement of pathogenic airborne viruses. J Hazard Mater 2021; 420: 126574.

16 Clausen JL. Lung volume equipment and infection control. Eur Respir J 1997; 10: 1928-1932.

17 Centers for Disease Control and Prevention. Scientific Brief: SARS-CoV-2 Transmission. 2021. www.cdc.gov/ coronavirus/2019-ncov/science/science-briefs/sars-cov-2-transmission.html Date last updated: 7 May 2021. Date last accessed: August 2021.

18 World Health Organization. Coronavirus disease (COVID-19): How is it transmitted? 2021. www.who.int/ news-room/q-a-detail/coronavirus-disease-covid-19-how-is-it-transmitted? Date last accessed: September 2021.

19 ARTP. COVID19 Infection control issues for lung function. Prepared by ARTP COVID19 Group. www.artp.org. uk/COVID19 Date last accessed: March 2021.

20 Li J, Jing G, Fink JB, et al. Airborne particulate concentrations during and after pulmonary function testing. Chest 2021; 159: 1570-1574. Epub 2020 Nov 1. PMID: 33144080.

21 Lindsley WG, King WP, Thewlis RE, et al. Dispersion and exposure to a cough-generated aerosol in a simulated medical examination room. J Occup Environ Hyg 2012; 9: 681-690.

22 Coleman KK, Tay DJW, Sen Tan K, et al. Viral load of SARS-CoV-2 in respiratory aerosols emitted by COVID-19 patients while breathing, talking, and singing. Clin Infect Dis 2021; in press [https://10.1093/cid/ ciab691]

23 Dhand R, Li J. Coughs and sneezes: their role in transmission of respiratory viral infections, including SARS-CoV-2. Am J Respir Crit Care Med 2020; 202: 651-659.

24 Kimberley L, Swan J, Perera M, et al. P36 Cough provoked by lung function testing: should lung function testing be treated as an aerosol generating procedure post COVID-19? BMJ 2021; 76: A104-A105. GINA. GINA guidance about COVID-19 and asthma. https://ginasthma.org/wp-content/uploads/2021/03/21 03_30-GINA-COVID-19-and-asthma.pdf Date last accessed: March 2021. Date last updated: 30 March 2021.

26 Tomisa G, Horváth A, Farkas Á, et al. Real-life measurement of size-fractionated aerosol concentration in a plethysmography box during the COVID-19 pandemic and estimation of the associated viral load. $J$ Hospital Infect 2021; 118: 7-14. ISSN 0195-6701,

Greening NJ, Larsson P, Ljungström E, et al. Small droplet emission in exhaled breath during different breathing manoeuvres: implications for clinical lung function testing during COVID-19. Allergy 2021; 76: 915-917.

28 Wu JKY, Ryan CM, Hiebert RJ, et al. Aerosol generation during pulmonary function testing: monitoring during different testing modalities. Can J Respir Crit Care Sleep Med 2021; in press [https://doi.org/10.1080/ 24745332.2021.1965926].

29 Hamilton F, Arnold D, Bzdek BR, et al. Aerosol generating procedures: are they of relevance for transmission of SARS-CoV-2? Lancet Respir Med 2021; 9: 687-689.

30 Brown J, Gregson FKA, Shrimpton A, et al. A quantitative evaluation of aerosol generation during tracheal intubation and extubation. Anaesthesia 2021; 76: 174-181.

31 Klompas M, Baker M, Rhee C. What is an aerosol-generating procedure? JAMA Surg 2021; 156: 113-114. http://dx.doi.org/10.1001/jamasurg.2020.6643.

32 Morley A, Bzdek B, Reid J, et al. Aerosol emission from the respiratory tract: an analysis of relative risks from oxygen delivery systems. medRxiv 2021; preprint [https://doi.org/10.1101/2021.01.29.21250552]

33 Saunders MJ, Haynes JM, McCormack MC, et al. How local SARS-CoV-2 prevalence shapes pulmonary function testing laboratory protocols and practices during the COVID-19 pandemic. Chest 2021; 160: 1241-1244.

34 Campbell F, Archer B, Laurenson-Schafer $\mathrm{H}$, et al. Increased transmissibility and global spread of SARS-CoV-2 variants of concern as at June 2021. Euro Surveill 2021; 26: 2100509.

35 Li Y, Liang M, Gao L, et al. Face masks to prevent transmission of COVID-19: A systematic review and meta-analysis. Am J Infect Control 2021; 49: 900-906. 
Gawn J, Clayton M, Makison C, et al. Evaluating the protection afforded by surgical masks against influenza bioaerosols. Gross protection of surgical masks compared to filtering facepiece respirators. Research Report RR619. Health and Safety Laboratory for the Health and Safety Executive, 2008. www.hse.gov.uk/research/ rrpdf/rr619.pdf. respiratory pathogens: an interdisciplinary, multi-stakeholder, evidence-based approach. J Occup Environ Med 2005; 47: 41-50.

38 Qian Y, Willeke K, Grinshpun SA, et al. Performance of N95 respirators: filtration efficiency for airborne microbial and inert particles. Am Ind Hyg Assoc J 1998; 59: 128-132.

39 Thomas JP, Srinivasan A, Wickramarachchi CS, et al. Evaluating the national PPE guidance for NHS healthcare workers during the COVID-19 pandemic. Clin Med 2020; 20: 242-247.

40 Cappa CD, Asadi S, Barreda S, et al. Expiratory aerosol particle escape from surgical masks due to imperfect sealing. Sci Rep 2021; 11: 12110.

41 Asadi S, Wexler AS, Cappa CD, et al. Aerosol emission and superemission during human speech increase with voice loudness. Sci Rep 2019; 9: 2348.

42 Morawska L, Johnson GR, Ristovski ZD, et al. Size distribution and sites of origin of droplets expelled from the human respiratory tract during expiratory activities. J Aerosol Sci 2009; 40: 256-269.

43 CDC. Guidelines for environmental infection control in healthcare facilities. www.cdc.gov/infectioncontrol/ guidelines/environmental/appendix/air.html\#b1 Date last accessed: October 2021.

44 WHO. Cleaning and disinfection of environmental surfaces in the context of COVID-19. WHO/2019-nCoV/ Disinfection/2020.1. Date last Accessed March 2021. https://www.who.int/publications/i/item/cleaning-anddisinfection-of-environmental-surfaces-inthe-context-of-covid-19 Date last accessed: March 2021. Sehulster LM, Chinn RYW, Arduino MJ, et al. Guidelines for environmental infection control in health-care facilities. Recommendations from CDC and the Healthcare Infection Control Practices Advisory Committee [HICPAC]. Chicago, IL: American Society for Healthcare Engineering/American Hospital Association; 2004. www.cdc.gov/infectioncontrol/pdf/guidelines/environmental-guidelines-P.pdf Christopherson DA, Yao WC, Lu M, et al. High-efficiency particulate air filters in the era of COVID-19: function and efficacy. Otolaryngol Head Neck Surg 2020; 163: 1153-1155.

47 Shaughnessy RJ, Sextro RG. What is an effective portable air cleaning device? A review. J Occup Environ Hyg 2006; 3: 169-181.

48 Greenhalgh T, Jimenez JL, Prather KA, et al. Ten scientific reasons in support of airborne transmission of SARS-CoV-2. Lancet 2021; 397: 1603-1605.

49 ARTP COVID-19 GROUP. Practical guidance for increasing Lung Function and Sleep activity during COVID-19 Endemic Phase. March 2020. www.artp.org.uk/News/artp-guidance-respiratory-function-testing-and-sleepservices-during-endemic-covid-19 Date last accessed: March 2021.

50 Jouffroy R, Jost D, Prunet B. Prehospital pulse oximetry: a red flag for early detection of silent hypoxemia in COVID-19 patients. Crit Care 2020; 24: 313.

51 Lauer SA, Grantz KH, Bi Q, et al. The incubation period of coronavirus disease 2019 (COVID-19) from publicly reported confirmed cases: estimation and application. Ann Intern Med 2020; 172: 577-582.

52 Xiao AT, Tong YX, Zhang S. Profile of RT-PCR for SARS-CoV-2: a preliminary study from 56 COVID-19 patients. Clin Infect Dis 2020; 71: 2249-2251.

53 Joynt GM, Wu WKK. Understanding COVID-19: what does viral RNA load really mean? Lancet Infect Dis 2020; 20: 635-636.

54 Wölfel R, Corman VM, Guggemos W, et al. Virological assessment of hospitalized patients with COVID-2019. Nature 2020; 581: 465-469.

55 Van Kampen JJA, van de Vijver DAMC, Fraaij PLA, et al. Duration and key determinants of infectious virus shedding in hospitalized patients with coronavirus disease-2019 (COVID-19). Nat Commun 2021; 12: 267.

56 Arons MM, Hatfield KM, Reddy SC, et al. Presymptomatic SARSCoV-2. Infections and transmission in a skilled nursing facility. N Engl J Med 2020; 382: 2081-2090.

57 Bullard J, Dust K, Funk D, et al. Predicting infectious SARS-CoV-2 from diagnostic samples. Clin Infect Dis 2020; 71: 2663-2666.

58 Young BE, Ong SWX, Ng LFP, et al. Viral dynamics and immune correlates of COVID-19 disease severity. Clinical Infectious Diseases Singapore 2019 Novel Coronavirus Outbreak Research Team, Viral Dynamics and Immune Correlates of Coronavirus Disease 2019 (COVID-19) Severity. Clin Infect Dis 2020; 73: e2932-e2942.

59 Haut Conseil de la santé publique. Avis relatif à la conduite à tenir en fonction du statut virologiqueSARS-CoV-2 chez une personne testée dans le cadre dudépistage ou du contact-tracing. 2020; 22. http://www.cpias-ile-de-france.fr/docprocom/doc/hcsp-contact-tracing-serologie-080720.pdf.

60 Haut Conseil de la santé publique. Avis relatif à la conduite à tenir face à un résultat de RT-PCR positif chez une personne ayant des antécédents d'infection par le SARS-CoV-2. 2020; 16. hcspa20200610_corsarco vantdecovetrtpcrpos.pdf. 
Faria NR, Mellan TA, Whittaker C, et al. Genomics and epidemiology of the P.1 SARS-CoV-2 lineage in Manaus, Brazil. Science 2021; 372: 815-821.

Davies NG, et al. Estimated transmissibility and impact of SARS-CoV-2 lineage B.1.1.7 in England. Science 2021; 372: eabg3055.

Volz E, Mishra S, Chand M, et al. Assessing transmissibility of SARS-CoV-2 lineage B.1.1.7 in England. Nature 2021; 593: 266-269.

Li B, Deng A, Li K, et al. Viral infection and transmission in a large, well-traced outbreak caused by the SARS-CoV-2 Delta variant. medRxiv 2021; preprint.

CDC. Interim Clinical Guidance for Management of Patients with Confirmed Coronavirus Disease (COVID-19). Section illness severity. www.cdc.gov/coronavirus/2019-ncov/hcp/clinical-guidance-management-patients. html Date last updated: 3 November 2020.

Jones NR, Qureshi ZU, Temple RJ, et al. Two metres or one: what is the evidence for physical distancing in covid-19? BMJ 2020; 370: m3223.

Osterholm M, Hedberg, CW, Moore, KA. Epidemiology of infectious diseases. In: Mandell GL, Bennett JE, Dolin R, eds. Principles and Practice of Infectious Diseases. Philadelphia, Churchill Livingstone, 2000; pp. 156-167.

ECDC. Heating, ventilation and air-conditioning systems in the context of COVID-19. www.ecdc.europa.eu/ en/publications-data/heating-ventilation-air-conditioning-systems-covid-19 Date last accessed: March 2021.

Bahl P, Doolan C, de Silva C, et al. Airborne or droplet precautions for health workers treating COVID-19? $J$ Infect Dis 2020; in press [https://doi.org/10.1093/infdis/jiaa189].

Qian, H, Miao, T, Liu, L, et al. Indoor transmission of SARS-CoV-2. Indoor Air 2021; 31: 639-645.

Li Y, Huang X, Yu ITS, et al. Role of air distribution in SARS transmission during the largest nosocomial outbreak in Hong Kong. Indoor Air 2005; 15: 83-95.

Hamner L. High SARS-CoV-2 attack rate following exposure at a choir practice-Skagit County, Washington, March 2020. MMWR Morbid Mortal Weekly Rep 2020; 69; 606-610.

Wanger J. ATS Pulmonary Function Laboratory Management and Procedure Manual. New York, American Thoracic Society, 2016.

CDC. Environmental Infection Control Guidelines. www.cdc.gov/infectioncontrol/guidelines/environmental/ index.html Date last accessed: March 2021.

Streifel AJ. Design and maintenance of hospital ventilation systems and prevention of airborne nosocomial infections. In: Mayhall CG, ed. Hospital Epidemiology and Infection Control. Philadelphia, Lippincott Williams \& Wilkins, 1999; pp. 1211-1221.

CDC. Appendix B. Air. Guidelines for Environmental Infection Control in Health-Care Facilities (2003). www. cdc.gov/infectioncontrol/guidelines/environmental/appendix/air.html Date last accessed: March 2021.

WHO. Roadmap to improve and ensure good indoor ventilation in the context of COVID-19. Geneva: World Health Organization; 2021. www.who.int/publications/i/item/9789240021280 Date last accessed: 1 March 2021.

ASHRAE. ASHRAE Position Document on Infectious Aerosols 2020. https://www.ashrae.org/file\%20library/ about/position\%20documents/pd_infectiousaerosols_2020.pdf Date last accessed: March 2021.

Atkinson J, Chartier Y, Pessoa-silva CL, et al. WHO Report: Natural Ventilation for Infection Control in Health-Care Settings. 2009. Geneva: World Health Organization. https://www.who.int/water_sanitation_health/ publications/natural_ventilation.pdf

Impellizzeri P, Campisi R, Spicuzza L, et al. Resumption of respiratory outpatient services in the COVID-19 era: Experience from Southern Italy Claudia Crimi MD, PhD. Am J Infect Control 2020; 48: 1087-1089.

Plantier L, Costes F, groupes de travail 'Fonction' et 'Alvéole' de la Société de pneumologie de langue française. Lung function testing under COVID-19: a position paper. Rev Mal Respir 2020; 37: 608-612. Epub 2020 Jun 5. PMID: 32600900; PMCID: PMC7274629.

Larsson P, Bake B, Wallin A, et al. The effect of exhalation flow on endogenous particle emission and phospholipid composition. Respir Physiol Neurobiol 2017; 243: 39-46. Epub 2017 May 11. PMID: 28502893.

Doremalen NV, Bushmaker T, Morris DH, et al. Aerosol and surface stability of SARS-CoV-2 as compared with SARS-CoV-1. N Engl J Med 2020; 382: 16.

Soriano JB, Anzueto A, Bosnic Anticevich S, et al. Face masks, respiratory patients and COVID-19. Eur Respir J 2020; 56: 2003325.

Bach CW. Effects of a Bacteriological Filter on VO2max Measured by a Computerized Metabolic System. Master's thesis, University of Tennessee, 2012. https://trace.tennessee.edu/utk_gradthes/1308

Marques MS, Fonseca A, Lima R, et al. Effect of a viral filter on cardiopulmonary exercise testing. Pulmonology 2021; in press. [https://doi.org/10.1016/j.pulmoe.2021.07.006].

Davis BE, Simonson SK, Blais CM, et al. Methacholine challenge testing: a novel method for measuring PD 20. Chest 2017; 152: 1251-1257.

Coates AL, Leung K, Dell S. Developing alternative delivery systems for methacholine challenge tests. J Aerosol Med Pul Drug Dev 2014; 27: 66-70. 
Ruppel GL. Aerosol use in the pulmonary function lab. Respir Care 2015; 60: 931-940.

Brannan JD, Anderson SD, Perry CP, et al. The safety and efficacy of inhaled dry powder mannitol as a bronchial provocation test for airway hyperresponsiveness: a phase 3 comparison study with hypertonic (4.5\%) saline. Respir Res 2005; 6: 144

Hallstrand TS, Leuppi JD, Joos G, et al. ERS technical standard on bronchial challenge testing: pathophysiology and methodology of indirect airway challenge testing. Eur Respir J 2018; 52: 1801033.

Unstead M, Stearn MD, Cramer D, et al. An audit into the efficacy of single-use bacterial viral filters for the prevention of equipment contamination during lung function assessment. Respir Med 2006; 100: 946-950.

Graham BL, Brusasco V, Burgos F, et al. 2017 ERS/ATS standards for single-breath carbon monoxide uptake in the lung. Eur Respir J 2017; 49: 1600016.

Graham BL, Steenbruggen I, Miller MR, et al. Standardization of Spirometry 2019 Update. An Official American Thoracic Society and European Respiratory Society Technical Statement. Am J Respir Crit Care Med 2019; 200: e70-e88.

Beydon N, Gochicoa L, Jones MJ, et al. Pediatric lung function testing during a pandemic: an international perspective. Paediatr Respir Rev 2020; 36: 106-108.

Wu Z, McGoogan JM. Characteristics of and important lessons from the coronavirus disease 2019 (COVID-19) outbreak in China. JAMA 2020; 323: 1239-1242.

Onder G, Rezza G, Brusaferro S. Case-fatality rate and characteristics of patients dying in relation to COVID-19 in Italy. JAMA 2020; 323: 1775-1776.

8 Spruit MA, Holland AE, Singh SJ, et al. COVID-19: Interim Guidance on Rehabilitation in the Hospital and Post-Hospital Phase from a European Respiratory Society and American Thoracic Society-coordinated International Task Force. Eur Respir J 2020; 56: 2002197.

Richardson $\mathrm{CH}$, Orr NJ, Ollosson SL, et al. Initiating home spirometry for children during the COVID-19 pandemic: a practical guide. Paediatr Respir Rev 2021; in press [https://doi.org/10.1016/j.prrv.2021.02.001].

European Lung Foundation. COVID19 Information. www.europeanlung.org/covid-19/covid-19-informationand-resources/covid-19-info Date last accessed: March 2021. 